\title{
Everybody knows: The importance of speaking up about witnessed workplace harassment and discrimination
}

\author{
Corresponding author: Camilla Elphick camilla.elphick@open.ac.uk ${ }^{1}$ \\ Rashid Minhas Rashid.minhas@uwl.ac.uk ${ }^{2}$; Julia Shaw j.shaw@ucl.ac.uk ${ }^{3}$ \\ ${ }^{1}$ The Open University, Walton Hall, Kents Hill, Milton Keynes, MK7 6AA \\ ${ }^{2}$ University of West London, St Mary's Rd, Ealing, London W5 5RF \\ ${ }^{3}$ University College London, Gower Street, London, WC1E 6BT
}

Since MeToo, light has been shed upon individual and societal consequences of workplace harassment and discrimination, and that at least $70 \%$ of victims fail to report it, but little is known about the role of witnesses in speaking up to support victims and contribute to healthier workplaces. An online survey of people who had witnessed workplace harassment or discrimination $(n=1147)$ was conducted to identify barriers and/or incentives to witness reporting, consequences of witness reporting, whether witness reporting mechanisms could or should be improved, and how to achieve this. The results revealed that incidents are often witnessed but seldom reported to HR by witnesses, although witnesses discuss them with colleagues. Barriers to reporting witnessed incidents, and consequences of experiencing them, overlap with those of victims, and consequences are worse when witnesses choose not to report. However, victim anonymity is compromised when witnesses discuss incidents without the victim's permission. Nevertheless, reporting witnessed incidents has the potential to create a positive shared identity of support in workplaces. Thus, one step to healthier workplaces is to include witnesses in the fight against harassment and discrimination. A novel model of harassment reporting (HRM) is developed to examine existing approaches of witness reporting and considerations for how to improve it are included.

Acknowledgments: We would like to thank Dr Zoe Walkington and Dr Ailsa Strathie for their suggestions after reading a draft of this manuscript.

This preprint has not yet been published (18062020). 


\section{EVERYBODY KNOWS: WITNESSING WORKPLACE HARASSMENT}

Workplace harassment was defined in 1976 as acts that repeatedly and persistently are aimed to torment, wear down, or frustrate, and which ultimately would provoke, frighten, intimidate, or bring discomfort to the person being harassed (Brodsky), and more recently, as interpersonal behaviour aimed at intentionally harming an employee in the workplace (Bowling \& Beehr, 2006). Research on workplace harassment appears under different labels, including bullying, interpersonal conflict, social undermining, and abuse (Keashly \& Jagatic, 2000), which refer to the same overall construct, the abusive treatment of an employee (Lapierre, Spector, \& Leck, 2005) ${ }^{1}$.

In a relatively short time, sexual harassment has been recognised as a serious social and organisational problem, affecting a large part of the population (e.g. Fitzgerald \& Shullman, 1993; Ilies, Hauserman, Schwochau, \& Stibal, 2003; Neall \& Tuckey, 2014; Willness, Steel, \& Lee, 2007). However, sexual harassment is only one form of inappropriate workplace behaviour. Others include name-calling, scapegoating, physical abuse, and work pressure, which are as frequent and as severe as sexual harassment (Brodsky, 1976).

Unfortunately, a number of research studies have noted that non-sexual harassment, including other forms of violence, aggression, and negative human interaction are rarely studied within

${ }^{1}$ Discrimination in the US and UK is defined as when an employer treats a person differently or worse because they are a member of a protected class or have a protected characteristic (e.g. race, colour, religion, gender, disability or age) or applies a 'provision, criterion or practice' equally to everyone/uses a neutral employment policy/practice that has a disproportionately adverse impact on members of a protected class or characteristic. 
an organisational context. It may even be that incidents ${ }^{2}$ of non-sexual workplace harassment have been reported as sexual harassment, as the only legitimate label (Neall \& Tuckey, 2014).

In recent years, workplace harassment has been the subject of extensive consideration from academics and policymakers (Nielsen, Glasø, \& Einarsen, 2017), as its prevalence has become a concern. For instance, figures suggest that anywhere between 38 to 60 percent of women (Ross, 2016) and 17 percent of men (EEOC, 2016) have experienced sexual harassment at work. The situation is even worse in the service industry (e.g. restaurants), with estimates of more than 90 percent of women experiencing sexual harassment (MSNBC, 2014). For some other types of harassment, the figures are even more distressing. For instance, the Harrison, Grant, and Herman (2012) reported that over 97 percent of LGBT workers have experienced workplace harassment.

It has long been established that workplace harassment ${ }^{3}$ is detrimental to health and well-being of employees (Deitch et al., 2003; Burgess, Lee, Tran, \& van Ryn, 2008; Taylor, Mcloughlin, Meyer, \& Brooke, 2013; Triana et al., 2015). It is associated with symptoms of PTSD (Willness, Steel, \& Lee, 2007), poor physical health (Bergman \& Henning, 2008), high blood pressure (Krieger et al., 2008), substance abuse (Silverschanz, Cortina, Konik, \&

${ }^{2}$ Incidents: situations where researchers have identified that workplace harassment has taken place.

${ }^{3}$ Workplace harassment: Henceforth, this term will be used to describe all forms of harassment and discrimination, unless a particular type is specified, as it is an established umbrella term for all types of workplace harassment and discrimination. 


\section{EVERYBODY KNOWS: WITNESSING WORKPLACE HARASSMENT}

Magley, 2008), cigarette smoking (Krieger, Smith, Naishadham, Hartman, \& Barbeau, 2005), work-to-life conflict (Minnotte, 2012), and insomnia (Ragins, Ehrhardt, Lyness, Murphy, \& Capman, 2017). There is also an accumulative effect, as health consequences escalate with workplace harassment (Lim \& Cortina, 2005), and women who experience both sexual harassment and workplace abuse are more likely to suffer from depression than those who have no experience of any form of workplace harassment (Marsh et al., 2009).

In addition to the high costs paid by people who are harassed (Buchanan \& Fitzgerald, 2008), workplace harassment detracts from the development and maintenance of a diverse and productive workplace (Branch et al., 2013). Contemporary workplaces are significantly more diverse than their historical counterparts (Konrad, 2016), and diversity has been shown to enhance organisational performance and lead to greater employee creativity and commitment (Rasul \& Rogger, 2015). However, as workplaces become more diverse, harassment can also be expected (Neall \& Tuckey, 2014), as it may be provoked by new kinds of interpersonal conflicts (Ray \& Preston, 2015).

Public awareness about workplace harassment has grown rapidly, thanks in part to campaigns such as MeToo (n.d.) and TimesUp (n.d.), which have also highlighted the issue of underreporting, focusing exclusively on victims ${ }^{4}$. However, research investigating the reporting of workplace harassment is less common. A comprehensive study, by the Equal Employment Opportunity Commission (EEOC, 2016), found that roughly 70 percent of those

${ }^{4}$ Victim: Henceforth, someone who has been the target of workplace harassment or discrimination will be referred to as a victim. 


\section{EVERYBODY KNOWS: WITNESSING WORKPLACE HARASSMENT}

who experience harassment in their workplace do not report it, even though staying silent has health and career consequences (Cortina \& Magley, 2003) and isolates the victim (Herbenick et al., 2019). The most common reason for victims not reporting is fear of consequences (AHRC, 2008; Charlesworth, McDonald, \& Cerise, 2011; Near, Rehg, Van Scotter, \& Miceli, 2004), which is justified when victims experience retaliation for reporting (Lee, Heilman, \& Near, 2004; TUC, 2019). Other common reasons are because employees do not know how to report (if policies or procedures are unclear or absent) or because of embarrassment (Banyard, Moynihan, \& Plante, 2007; TUC), especially when reporting incidences of sexual harassment. Victims also sometimes think that an incident can be handled by themselves (AHRC; Charlesworth et al.,; Finn, 2004), nothing can be done (Near et al.,), they do not know to whom to report (Finn), or they fear of not being believed (Dougherty, 2000; TUC).

The fear of not being believed (Dougherty, 2000) and the focus on victim reporting both give the impression that workplace harassment occurs in secret, yet the EHRC (2016) found that 32 percent of BAME employees in the UK had witnessed ${ }^{5}$ or experienced workplace harassment in 2016, and Rai and Agarwal (2017) found that 56 percent of participants in India had witnessed bullying (in a six month period).

It appears that victims are generally under pressure to act alone even if incidents are witnessed, although witnesses can play a supporting role by reporting on the behalf of the

${ }^{5}$ Witness: Someone who has been classified by researchers as having witnessed harassment directly or indirectly. 


\section{EVERYBODY KNOWS: WITNESSING WORKPLACE HARASSMENT}

victim, or by providing supporting evidence. Indeed, Bowes-Sperry and O’Leary-Kelly (2005) found that those who witness sexual harassment can be powerful forces in confronting and reducing it. This is supported by Rayner and Bowes-Sperry (2008) and Paull, Omari and Standen (2010), who proposed that workplace harassment training should include witness roles, as involving witnesses is the most likely remedy. Witness reporting could also benefit witnesses, as merely being aware of workplace harassment can increase their stress and absenteeism, and lower their commitment to the organisation (Ragins, Ehrhardt, Lyness, Murphy, \& Capman, 2017), which could be mitigated by reporting it. However, like victims, witnesses rarely report (Good, MossRacusin, \& Sanchez, 2012).

It is also worth taking steps to overcome reluctance to report, as the stigmatisation of groups such as LGBT(Q+) communities (Potter, Fountain, \& Stapleton, 2012), and victim isolation (Herbenick et al., 2019), can be amplified if witnesses do not intervene, but can be reduced if witnesses support the victim. For instance, D' Cruz and Noronha (2011) found that friendships between victims and witnesses developed after an incident, supporting the idea that work-related issues draw colleagues together (Sias \& Jablin, 1995). However, if incidents are discussed among colleagues without the victim's knowledge or consent, their isolation can be amplified. Discussion of incidents among colleagues is also likely to have a social contagion effect (Christakis \& Fowler, 2013) on individual attitudes and groups (Barsade, 2002), amplifying the toxic environment for all.

There are several possible reasons for reluctance to report, one of which is known as the 'Bystander Effect', which expresses the idea that people do not intervene (when they witness an incident or violation of community norms in the presence of others), as they believe others will intervene (Latané \& Darley, 1970). One explanation for non-intervention 


\section{EVERYBODY KNOWS: WITNESSING WORKPLACE HARASSMENT}

is that witnesses treat involvement as a cost-benefit choice (e.g. Miceli \& Near, 1988). For instance, witnesses balance considerations such as not wanting to be retaliated against by the perpetrator or the organisation (Hulin et al., 1991), and the potential commitment involved, with considerations about potential long-term disadvantages of not speaking up (Bandura, 1999) (e.g. guilt, shame, or regret) compared with the benefits of doing so for the victim, themselves, and other colleagues (e.g. pride, gratitude, or praise), and favour nonintervention.

However, Levine and Manning (2013) found that shared social identity increases the likelihood that bystanders will intervene. This echoes work by Reicher and Hopkins (2000), that social solidarity is increased when identities are shared. Other bystander research (e.g. Ashburn-Nardo, Blanchar, Petersson, Morris, \& Goodwin, 2014) proposes that perceived responsibility, costs, and being able to choose a suitable action also influence witnesses' decisions to report. Thus, by creating workplaces with a positive sense of shared identity and responsibility, social solidarity, and agency, witnesses of harassment might be encouraged to support the victim by speaking out. If so, this could help to improve the wellbeing and organisational commitment of both victims and witnesses, and improve workplace climates.

Finally, we briefly consider witnesses' insights into ways that reporting processes could be improved, such as using cyber reporting mechanisms for witness reporting. Machine conversation systems or 'chatbots' are increasingly being adopted for managing mental health (e.g. Woebot, n.d.), and are used in many fields (Brandtzaeg \& Følstad, 2017). They have some advantages over reporting to humans, including allowing for anonymous reporting; providing different reporting pathways; ensuring that users are not disbelieved or judged when making a report (by minimising implicit biases), and are available at any time. 
Online reporting is recommended by the EHRC (2018), for victims to report sexual harassment, and has recently been scaled to include all forms of workplace harassment and witness reporting (e.g. Talk to Spot n.d.; Vault, n.d.). Therefore, we were interested in investigating whether (and what kind of) reporting approaches are (un)desired by witnesses, to improve witness reporting and to encourage it in the first place.

The present research thus investigates the witnessing of workplace harassment, and the barriers to witness reporting. The four main aims are i) to assess how commonly witnesses report incidences, ii) to identify barriers to witness reporting, iii) to examine witness reporting decisions and their consequences, and iv) to ask what witnesses think organizations should do to improve witness reporting processes. Understanding witnesses' experiences could help organizations to tackle workplace harassment, improve communication between employees and HR, and build healthier workplaces. We conclude with five practical considerations for workplaces.

\section{Method}

\section{Participants}

Participants were recruited for an interactive online survey via Positly (n.d.), Survey Circle (n.d.) and social media (Twitter and Facebook), with the support of relevant NGOs and non-profit organisations: iHollaback (n.d.); Pregnant then Screwed (n.d.); All Together Now (n.d.); Diversity Watch (n.d.); Women in the City (n.d.). Most participants were from the US, but the survey was run internationally, and included participants from the UK, Canada and Australia. 


\section{EVERYBODY KNOWS: WITNESSING WORKPLACE HARASSMENT}

The survey was run five times. The first run was a pilot $(n=56)$. Following inspection of the results, this was followed by a main study $(n=661)$. As no changes were made between the two, we collapsed the data $(n=717)$ and called this survey 1 .

Simultaneously, we ran a version where the questions were flipped, to check for bias $(\mathrm{n}=$ 61), and called this survey 2. Finally, after inspecting the results for themes that had been mentioned in free text sections, we ran a third version. This version contained a pilot $(\mathrm{n}=59)$ and main study $(n=310)$, where the data were collapsed $(n=369)$ to form survey 3 . This amounted to a total of 1147 participants, 1106 of whom continued after consenting.

We include data from all surveys where possible, but mainly describe data from survey 3 to simplify the results, as they largely replicated those of the previous surveys, while being more expansive. Each analysis is clearly labelled with the survey and sample size.

\section{Table 1.}

The number of participants who consented to participate in each version, the method and country of recruitment, participant payment, and descriptive statistics.

\begin{tabular}{|c|c|c|c|c|c|}
\hline Survey & $\begin{array}{l}\text { 1a. Pilot } \\
\text { first } \\
\text { survey }\end{array}$ & $\begin{array}{l}\text { 1b. Main } \\
\text { first survey }\end{array}$ & $\begin{array}{l}\text { 2. Flipped } \\
\text { survey }\end{array}$ & $\begin{array}{l}\text { 3a. Pilot final } \\
\text { survey }\end{array}$ & $\begin{array}{l}\text { 3b. Main final } \\
\text { survey }\end{array}$ \\
\hline Number & 56 & 661 & 61 & 59 & 310 \\
\hline Method & $\begin{array}{l}\text { Twitter, } \\
\text { FB, } \\
\text { Survey } \\
\text { Circle \& } \\
\text { NGOS }\end{array}$ & Positly & $\begin{array}{l}\text { Twitter, } \\
\text { Survey } \\
\text { Circle, } \\
\text { NGOS \& } \\
\text { Positly }\end{array}$ & Positly & Positly \\
\hline Country & $\begin{array}{l}\text { UK, } \\
\text { Australia }\end{array}$ & US & $\begin{array}{l}\text { UK, US, } \\
\text { Australia }\end{array}$ & US & US \\
\hline Payment & none & $\$ 1.20$ & $\$ 1.20$ & $\$ 1.20$ & $\$ 1.20$ \\
\hline Statistics & none & $\begin{array}{l}265 \text { male, } \\
256 \text { female, } \\
2 \text { other }\end{array}$ & none & $\begin{array}{l}23 \mathrm{~m} \& 20 \mathrm{f} \\
\text { aged } 23-68, \\
(M=41.35 \\
S D=10.90)\end{array}$ & $\begin{array}{l}130 \mathrm{~m}, 119 \mathrm{f}, 1 \\
\text { other, aged } 20- \\
72,(M=40.06 \text {, } \\
S D=11.53)\end{array}$ \\
\hline
\end{tabular}


EVERYBODY KNOWS: WITNESSING WORKPLACE HARASSMENT

\section{Materials and Procedure}

The surveys were built using Qualtrics (n.d.). The questions were informed by reviewing literature investigating workplace harassment. There were 54 questions in surveys 1 and 2, and 141 questions in survey 3 . However, as there were survey branches, no participant answered every question, and the number of questions asked differed in each branch. Most questions were forced choice, but each section also contained an optional free text section, where participants could add what they wanted in their own words. Participants could take as long as they needed to respond (mean completion time $=8$ minutes).

We used themes identified in the free text from surveys 1 and 2 to develop survey 3. Therefore, we only report data from survey 3 for the main analyses. Some quotes from are included in the results to support our analyses.

The surveys were conducted between February 2019 and May 2019. The procedure for participants completing all three surveys was the same. After clicking the survey link, participants were taken to the online survey builder, Qualtrics (n.d.), where they were given information and asked to provide their informed consent. The survey began with an explanation of harassment and discrimination, and examples of each. Participants were also given our definitions of 'witness' and 'victim' to help them answer the questions:

Witness: This study is looking at witnesses of harassment or discrimination. When we use the term witness, we mean someone who has seen, heard, or knows of another person being harassed or discriminated against. 


\section{EVERYBODY KNOWS: WITNESSING WORKPLACE HARASSMENT}

Victim: When we use the term victim, we mean someone who has been the target of harassment or discrimination themselves.

Therefore, when the word "victim" is used, we refer to individuals' responses to questions after reading the definition provided. When the term "witness" is used, it refers to individuals who answered "yes" to the question, "Have you ever witnessed any incident(s) of harassment or discrimination in the workplace?" after reading the definition provided.

This research received ethical approval from the university ethics board.

\section{Results}

\section{Witnesses to workplace harassment and discrimination: all survey versions.}

All consenting participants ( $\mathrm{n}=1147)$ were first asked; "Have you ever witnessed any incident(s) of harassment or discrimination in the workplace?". 1106 answered using one of four options: Yes, I was there when it happened (direct witnessing); I wasn't there, but I heard about it (indirect witnessing); No; I was the victim, and I would like to describe what happened to me (these participants were given the option to leave he survey and describe what had happened to them to a chatbot (Talk to Spot, n.d.) on a separate website rather than to continue with the survey, or to continue with the survey by describing incidents that they had witnessed. (All participants could access the chatbot at the end of the survey).

As the survey explicitly said that we were investigating the witnessing of workplace harassment, only data from participants who had witnessed workplace harassment (directly or indirectly) were included, resulting in 81 percent of participants (895) in the final sample. 
Table 2.

Participants who responded that they had (directly or indirectly) witnessed any incident(s) of workplace harassment in the workplace ${ }^{6}$

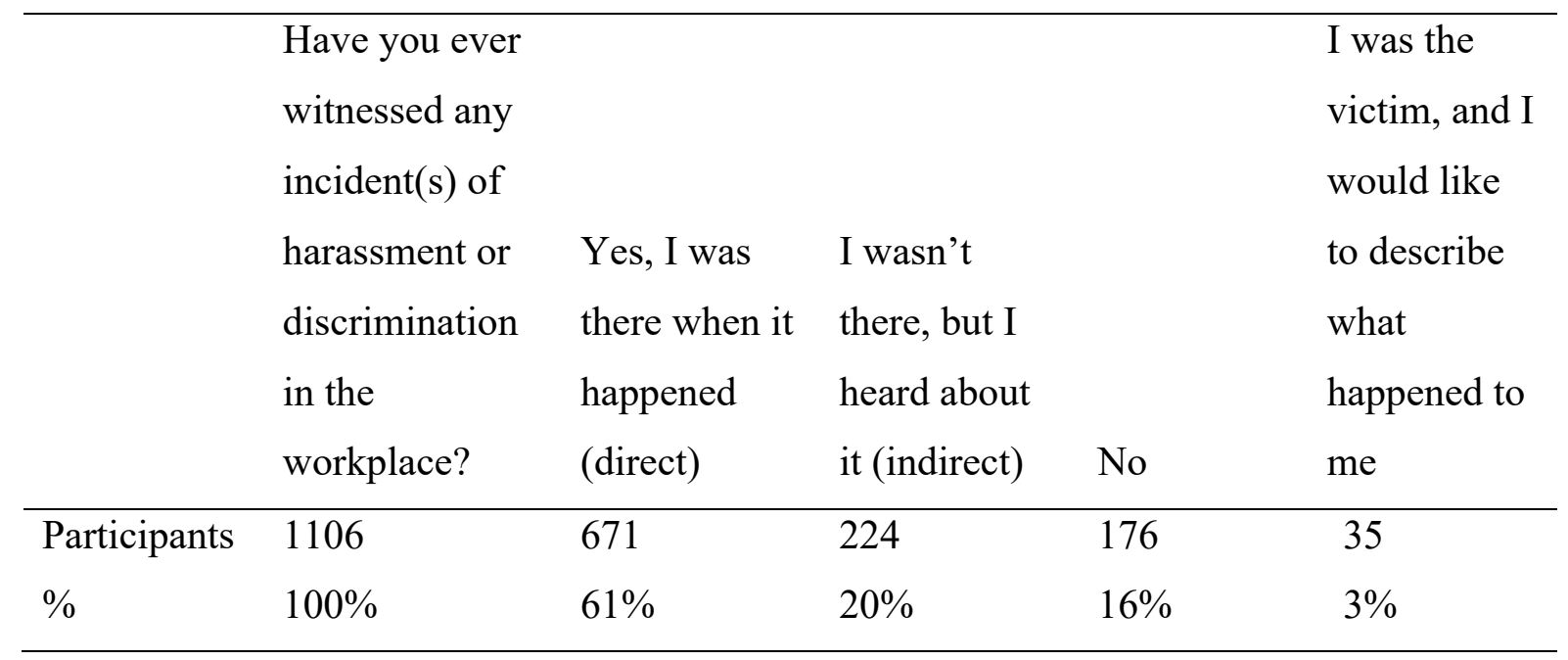

\section{When the incident(s) were witnessed.}

All participants in the final sample $(\mathrm{n}=895)$ were asked, "Roughly when did the incident(s) happen?" and 650 (73 percent) responded: 21 percent that the incident(s) had occurred more than five years ago; 41 percent that the incident(s) had occurred more than a year ago (within five years); 38 percent that it/they had happened within the past year. A Chi Square Goodness-of-Fit test revealed that the number of witnessed incidents were significantly different $\left(X^{2}=50.44, p<.001\right)$, with most incidents (79 percent) occurring within five years.

\footnotetext{
${ }^{6}$ NOTE: This survey explicitly asked for witnesses of harassment, so the figures do not represent the number (or proportion) of people in the general population who have been victims.
} 
Table 3.

When the incidents described occurred

\begin{tabular}{lllll}
\hline & $\begin{array}{l}\text { Roughly when did the incident(s) } \\
\text { happen? }\end{array}$ & $\begin{array}{l}\text { More } \\
\text { than 5 } \\
\text { years }\end{array}$ & $\begin{array}{l}\text { Less than } \\
5 \text { years }\end{array}$ & $\begin{array}{l}\text { Less than } \\
\text { 1 year }\end{array}$ \\
\hline Participants & 650 & 133 & 268 & 246 \\
$\%$ & $100 \%$ & $21 \%$ & $41 \%$ & $38 \%$ \\
\hline
\end{tabular}

Therefore, while recent incidents may be more likely to be described in a survey than less recent incidents, the results suggest that inappropriate workplace behaviour continues to be a problem in the wake of MeToo.

The people witnesses talk to about the incident(s): all survey versions.

The EEOC (2016) estimated that 70 percent of victims fail to report workplace harassment. It was important to know whether witnesses are also failing to report to HR, so we used the EEOC figure as a guide. We were also interested in knowing whether any failure to report to HR reflects witnesses' decisions about discussing incidents with other people. In other words, if witnesses fail to report to HR, it is important to know whether they are talking to other people instead, or whether incidents are not discussed with anybody.

To answer these questions, all participants in the final sample $(n=895)$ were asked first, “Did you make a formal report to the HR department?”, and 887 responded. A Binomial test was used to compare the proportion of participants who said they had not reported the incident(s) to HR in the current research to the estimated 70 percent of victims that fail to report workplace harassment (EEOC, 2016). It revealed that the proportion of 


\section{EVERYBODY KNOWS: WITNESSING WORKPLACE HARASSMENT}

participants in the current research who did not report to HR was significantly greater than the proportion of victims that the EEOC estimated do not report (77 percent, $p<.001$ ).

Participants were also asked, "Did you tell anyone at work other than HR (e.g. your line manager or a colleague)?", and 863 responded. As 77 percent of the present participants responded that they had not reported to HR, an analysis of the proportion of participants who responded that they had not told colleagues was compared to this figure. A Binomial test revealed that the proportion of participants that did not tell colleagues was significantly smaller (53 percent, $p<.001$ ) than those who did not report to HR.

Finally, participants were asked, "Did you tell anyone outside your workplace?” and 614 responded. As 53 percent had responded that they did not talk to colleagues, an analysis of the proportion of witnesses who responded that they had not told people outside the workplace (e.g. friends or family) was compared to this figure. A Binomial test revealed that the proportion of participants that did not tell people outside work was significantly smaller (35 percent, $p<.001$ ) than those who did not tell colleagues. Thus, witnesses were talking about incidents significantly more to people outside the workplace than inside it, and were more likely to speak to colleagues than to report to HR. 


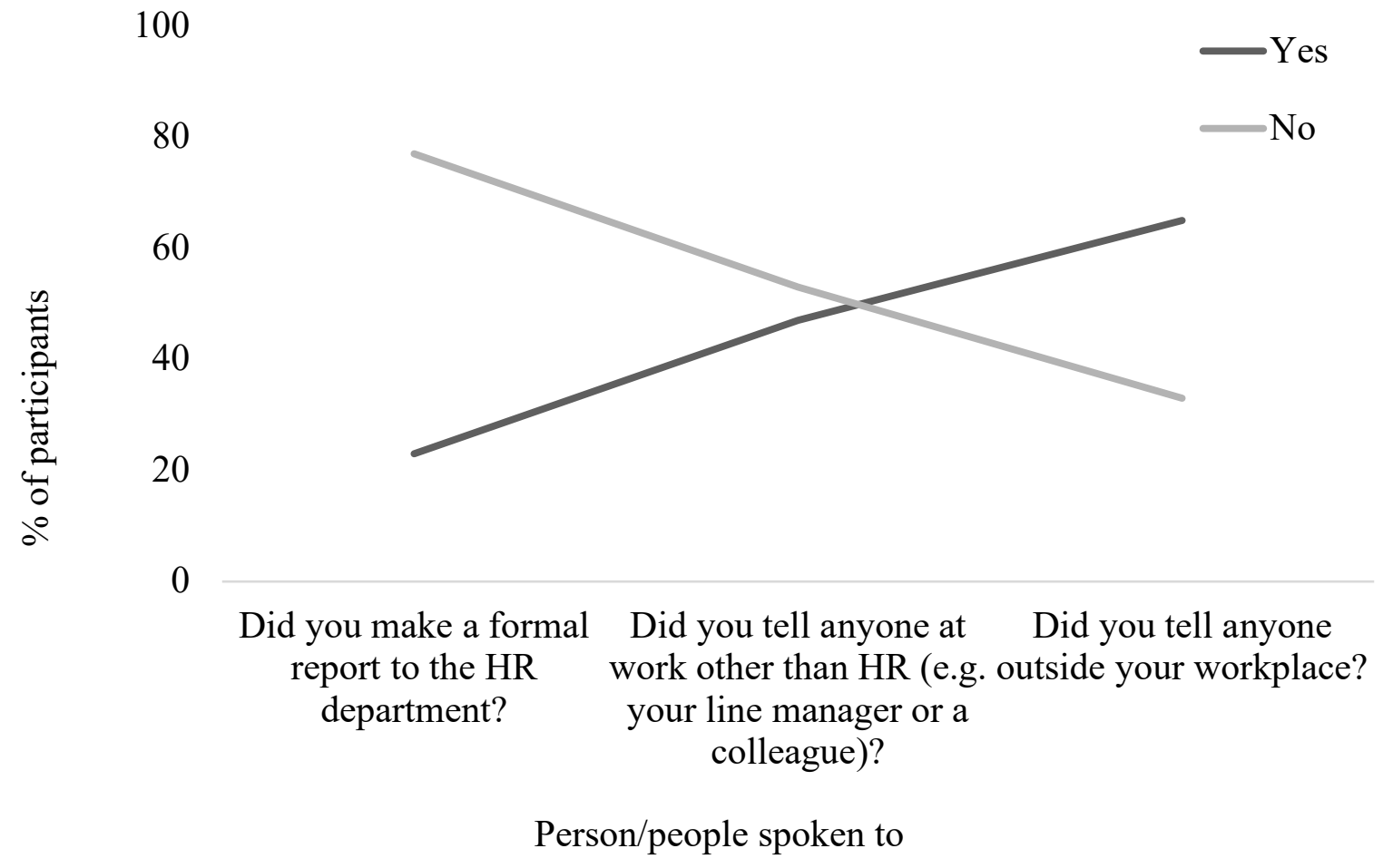

Figure 1. The proportion of participants who indicated that they had/had not discussed the incident(s).

The people outside the workplace to whom witnesses talk: all survey versions.

All participants in the final sample $(\mathrm{n}=895)$ were also asked, "Did you tell anyone outside your workplace?". Participants were given the following options:

My friend(s)

My family member(s)

A lawyer or other expert

Other

No

I can't remember 


\section{EVERYBODY KNOWS: WITNESSING WORKPLACE HARASSMENT}

Participants could choose as many or few options as they wished. Of the 614 participants that answered, 65 percent remembered talking to someone outside work. The overwhelming majority chose to speak to family members or friends. The combined results suggest that witnesses confide in people they trust rather than discuss the incidents to start a formal process. This means that incidences are known about in workplaces, albeit not by HR.

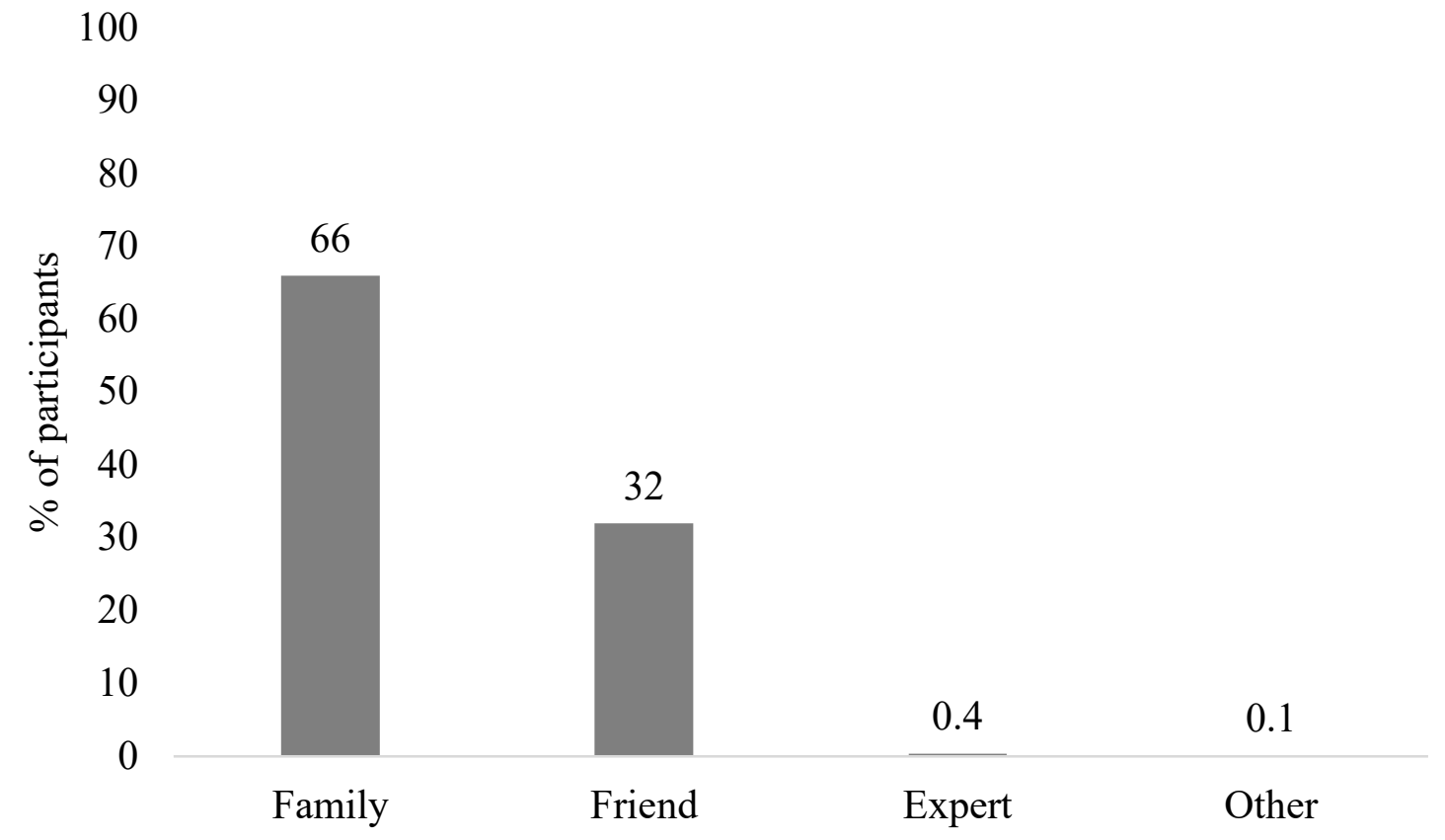

Person/people spoken to outside the workplace

Figure 2. The proportion of people that participants spoke to outside the workplace.

The colleagues to whom witnesses talk: Survey 3.

Survey 3 was the most comprehensive version, and several steps had been taken to minimise potential bias. These included exploring the qualitative data in the previous surveys, and inspecting the results of survey 2 , where the questions were flipped. Despite the changes between the three versions, the results were similar for all three. Therefore, for simplicity, only the results from survey 3 are evaluated in the remaining analyses. 


\section{EVERYBODY KNOWS: WITNESSING WORKPLACE HARASSMENT}

Participants who responded to the question "Did you tell anyone at work other than HR (e.g. your line manager or a colleague)?" were given the following options from which they could choose as many/few as they wished $(\mathrm{n}=177)$ :

I made a formal report to someone in management

I informed someone in management (informally)

I made a formal report to someone at the highest level of the organisation

I informed someone at the highest level of the organisation (informally)

I informed a colleague who was in my team

I informed a colleague who was not in my team

I spoke to the victim

Other

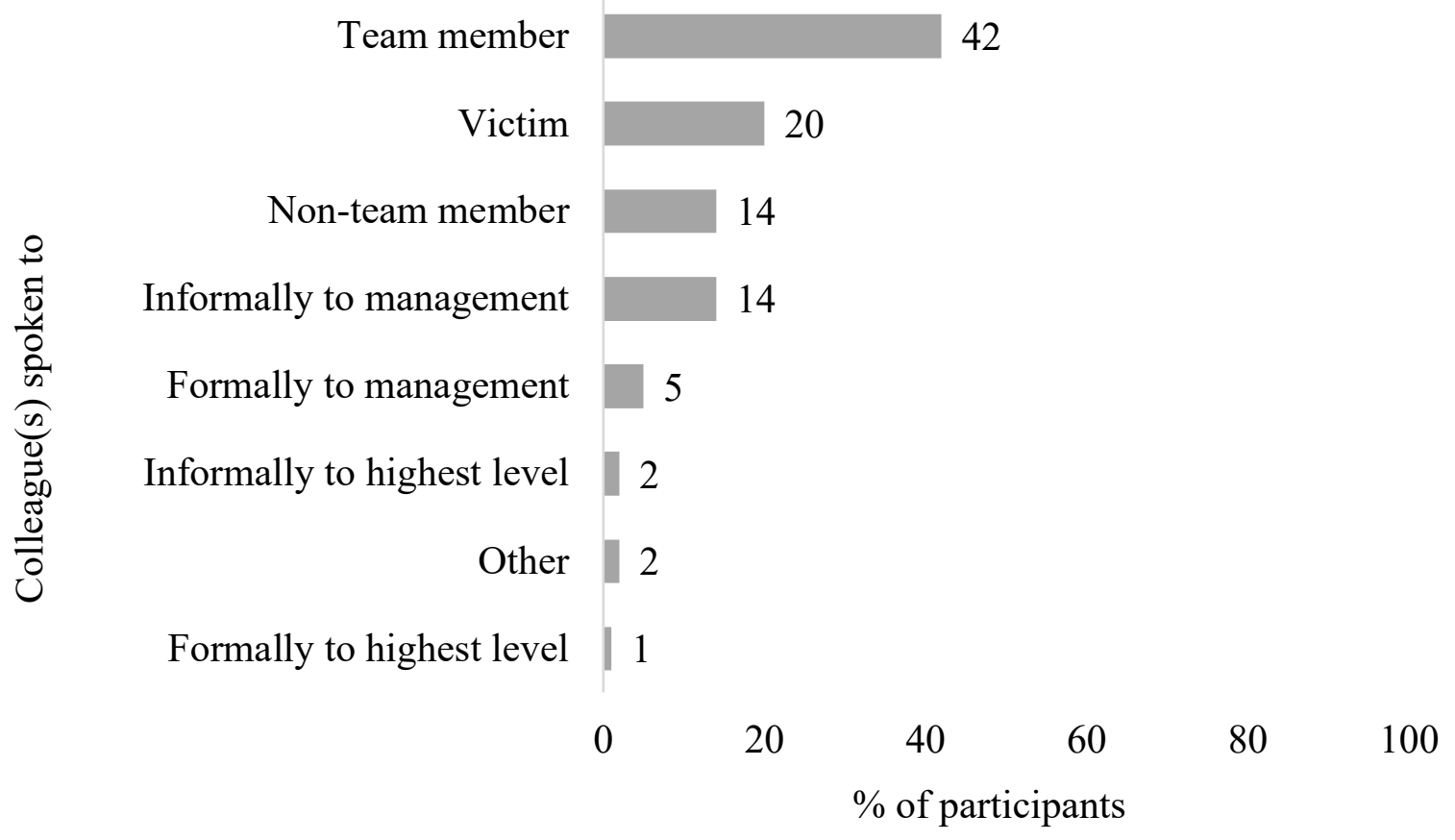

Figure 3. The colleagues that witnesses spoke to (survey 3). 


\section{EVERYBODY KNOWS: WITNESSING WORKPLACE HARASSMENT}

Most participants chose to talk to a team member. Therefore, witnesses were less likely to discuss the incidents as the process became more formal and/or the power of the person to whom they were talking increased. In other words, speaking to colleagues of higher rank was possibly seen as a form of reporting, rather than social support.

\section{Why witnesses talk about incidents to people in the workplace: Survey 3.}

It was important to understand why witnesses discuss incidents at work, to understand better the ways that formal and informal settings might influence motivations to discuss them; to understand better the experiences of witnessing workplace harassment; and to find ways to encourage witness reporting.

\section{Why witnesses report to HR: Survey 3.}

Participants who responded that they had reported to HR were asked why they made this decision, and 66 responded. They were given the following options:

Because everyone else was afraid to report

Because I dislike unfair treatment

Because the workplace culture needs to change

Because everyone else was afraid

Because I wanted to reduce the burden on the victim to report alone

Because the perpetrator needed to stop

Because I had previous experience as a victim

Because I wanted to offer support to the victim 
EVERYBODY KNOWS: WITNESSING WORKPLACE HARASSMENT

The victim asked me to

I wanted advice

I wanted support

I wanted evidence/protection

Everyone knew except HR

It affected us all

Participants could respond with one of these statements:

I reported to HR for this reason

I did NOT report to HR for this reason

I'm not sure if I reported to HR for this reason 


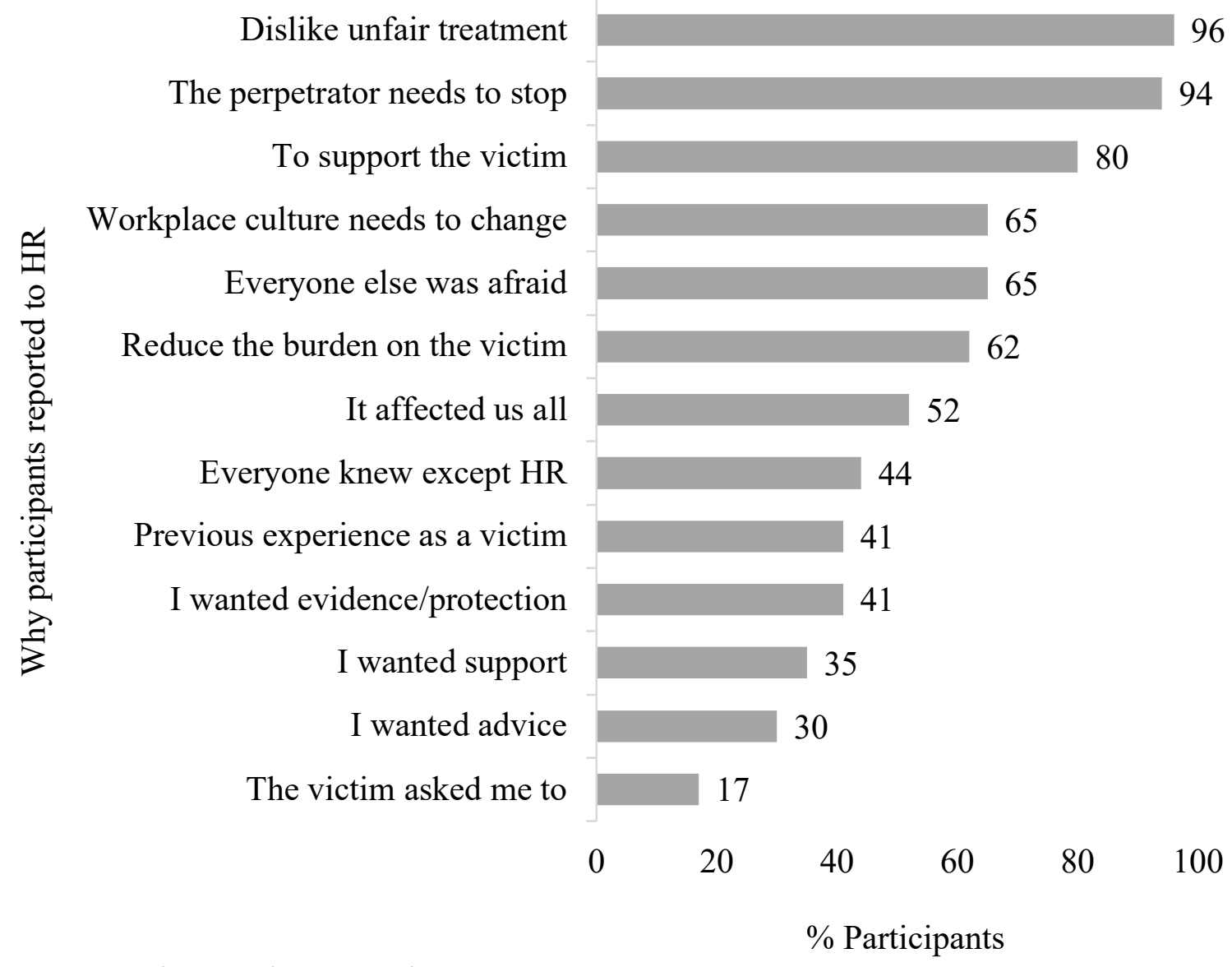

Figure 4. Why people reported to HR (survey 3).

Inspection of figure 4 revealed that the top three reasons were Because I dislike unfair treatment; Because the perpetrator needed to stop; and Because I wanted to offer support to the victim. Therefore, witnesses seemed to be driven to report for altruistic reasons. However, only 17 percent said they had reported because they had been asked to do so by the victim, this is of concern if victims are not aware that the witness has reported. Figure 4 also reveals that incidents of workplace harassment are often common knowledge among colleagues, as about two thirds of participants selected Because everyone else was afraid; about half selected It affected us all; and just under half selected Everyone knew except HR. This indicates that workplace harassment is a shared experience among co-workers, but not HR. 


\section{Why witnesses tell colleagues: Survey 3.}

Participants that had talked to colleagues about incidents were asked why, and 106 responded. Most options were the same as those offered about decisions to report to HR, but participants were also given the following options:

Everybody knew anyway

It was funny or I condoned it

It was fun to gossip

A Chi-Square 'Goodness-of-Fit' test was run to compare selections made about reporting to HR and telling colleagues, which showed that there were significantly different reasons for discussing incidents with HR than with colleagues, $X^{2}=22.93, p=.02$. 


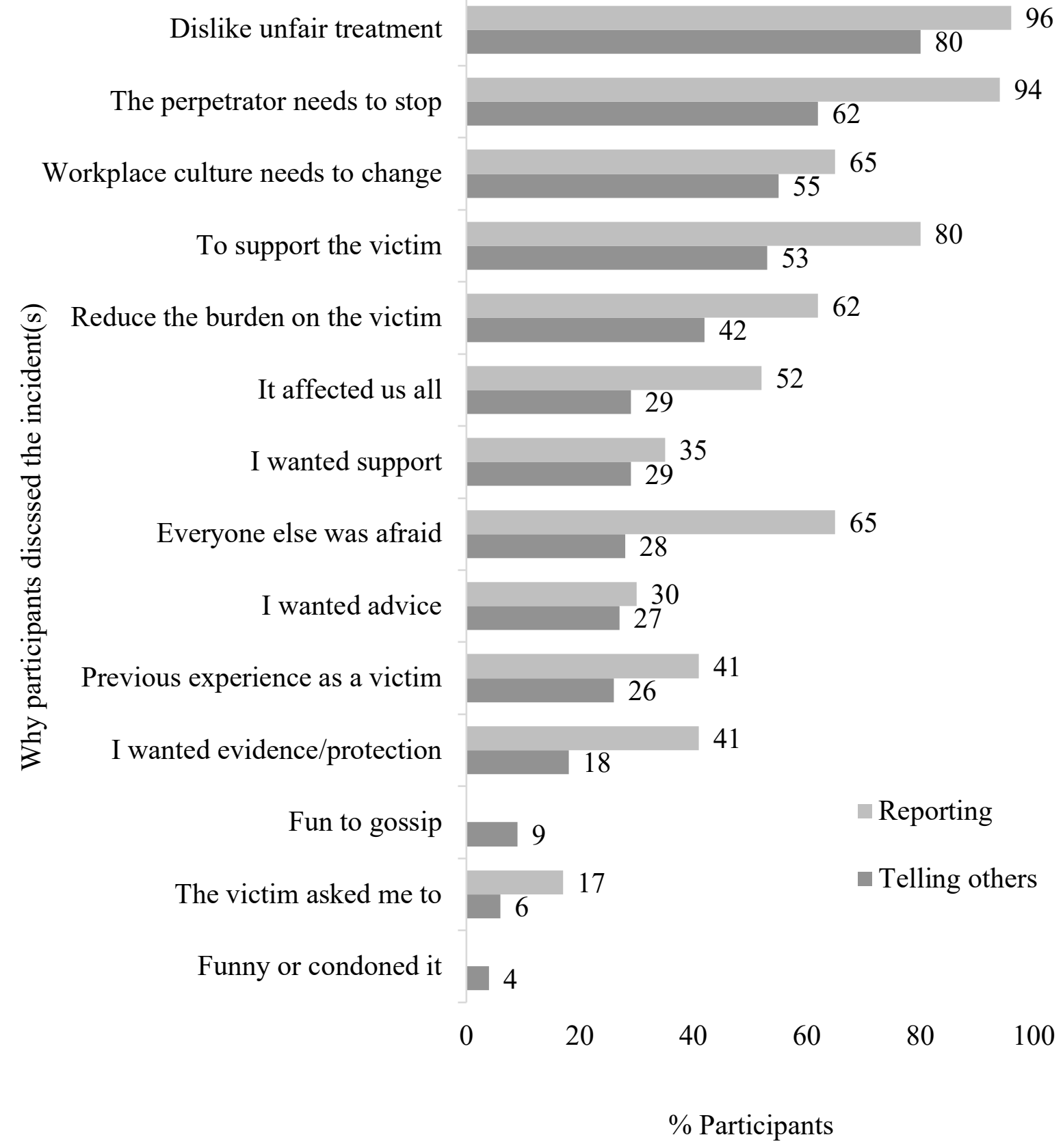

Figure 5. Comparison of why participants reported to HR and why they told colleagues.

Inspection of figure 5 reveals that in most cases, larger proportions of witnesses selected the options as reasons for reporting to HR rather than telling colleagues. However, the top two most common reasons were the same for both: Because I dislike unfair treatment, and Because the perpetrator needed to stop. 


\section{EVERYBODY KNOWS: WITNESSING WORKPLACE HARASSMENT}

This indicates that the different reasons for reporting to HR compared to discussing incidents with colleagues is largely driven, when reporting to HR, by the need to support the victim; for evidence or protection; and the effect the incident(s) had on others in the workplace (e.g. fear). Also, the additional option Everybody knew anyway that was selected by almost half the participants as a reason for discussing the incidents with colleagues adds weight to the idea that incidents of workplace harassment are widely known among colleagues.

\section{Why witnesses choose not to talk about the incident(s) to people in the workplace.}

It was also important to know what barriers witnesses face when making decisions about discussing incidents at work, in order to overcome them.

\section{Why witnesses choose to not report to HR: Survey 3.}

Participants who responded that they did not report to HR $(n=227)$ were asked "We would be interested to know why you did not tell HR.", and given the following options:

Because I was worried about the consequences

Because I did not want to interfere

Because I was worried I would not be believed

Because I did not want to be seen as a 'snitch'

Because I did not know how to report

Because I did not know that witnesses could report

Because the reporting process is too complicated 
EVERYBODY KNOWS: WITNESSING WORKPLACE HARASSMENT

Because I did not have time

Everybody already knew

I thought it was the victim's responsibility to report

There was no point, as nothing would be done

Powerful people were involved

HR was involved

There was no reporting mechanism for witnesses/Witnesses are not allowed to report

Participants had three response options to each item:

This was a reason

This was not a reason

I'm not sure if this was a reason 


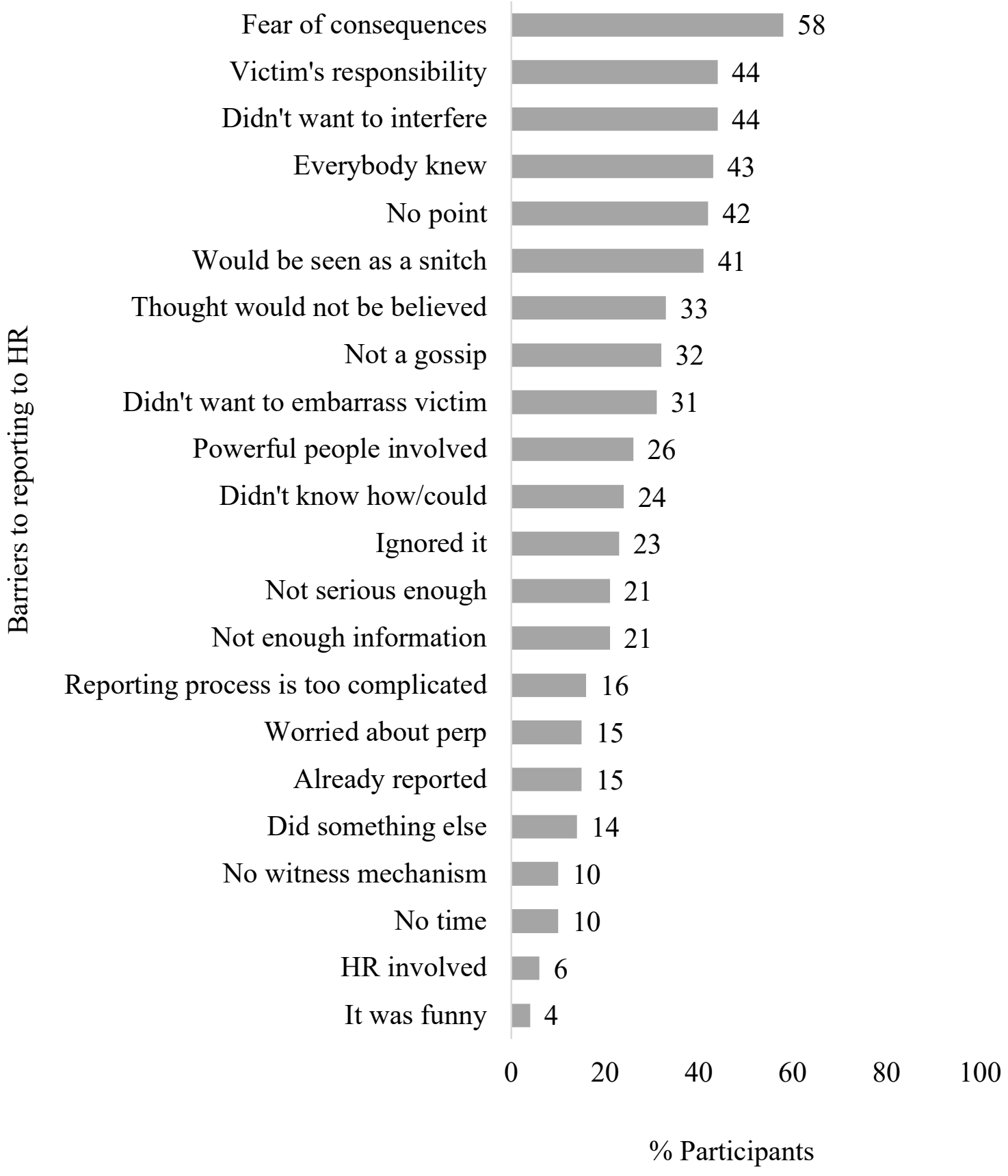

Figure 6. Barriers to reporting (survey 3).

Figure six revealed that, like victims, the most common reason for not reporting to HR was Because I was worried about the consequences, followed by Because I did not want to interfere; I thought it was the victim's responsibility to report; Everybody already knew; and There was no point, as nothing would be done. Participants also did not report because 
Powerful people were involved (26 percent), because There was no reporting mechanism for witnesses/Witnesses are not allowed to report (10 percent), and because HR was involved (six percent). Thus, the most common barrier to witness reporting, fear of the consequences, was the same as the most common barrier to victim reporting. However, witnesses are sometimes also hampered by a lack of reporting mechanism or permission to report.

\section{Why witnesses choose not to tell colleagues: Survey 3.}

When participants responded that they had not told colleagues, we asked why not, and 96 responded. Most of the items were the same as those for HR reporting decisions, but the following items were also included:

I did not want to gossip

I did not know who to tell

HR should deal with it

HR was already handling it

The proportions of participants who selected the items were compared to the items selected as reasons for not reporting to HR. A Chi-Square 'Goodness-of-Fit' test was run to compare reasons for not reporting to HR and for not telling colleagues. This showed that there were significantly different reasons for choosing not to discuss incidents with HR compared with colleagues, $X^{2}=52.97, p<.001$. 


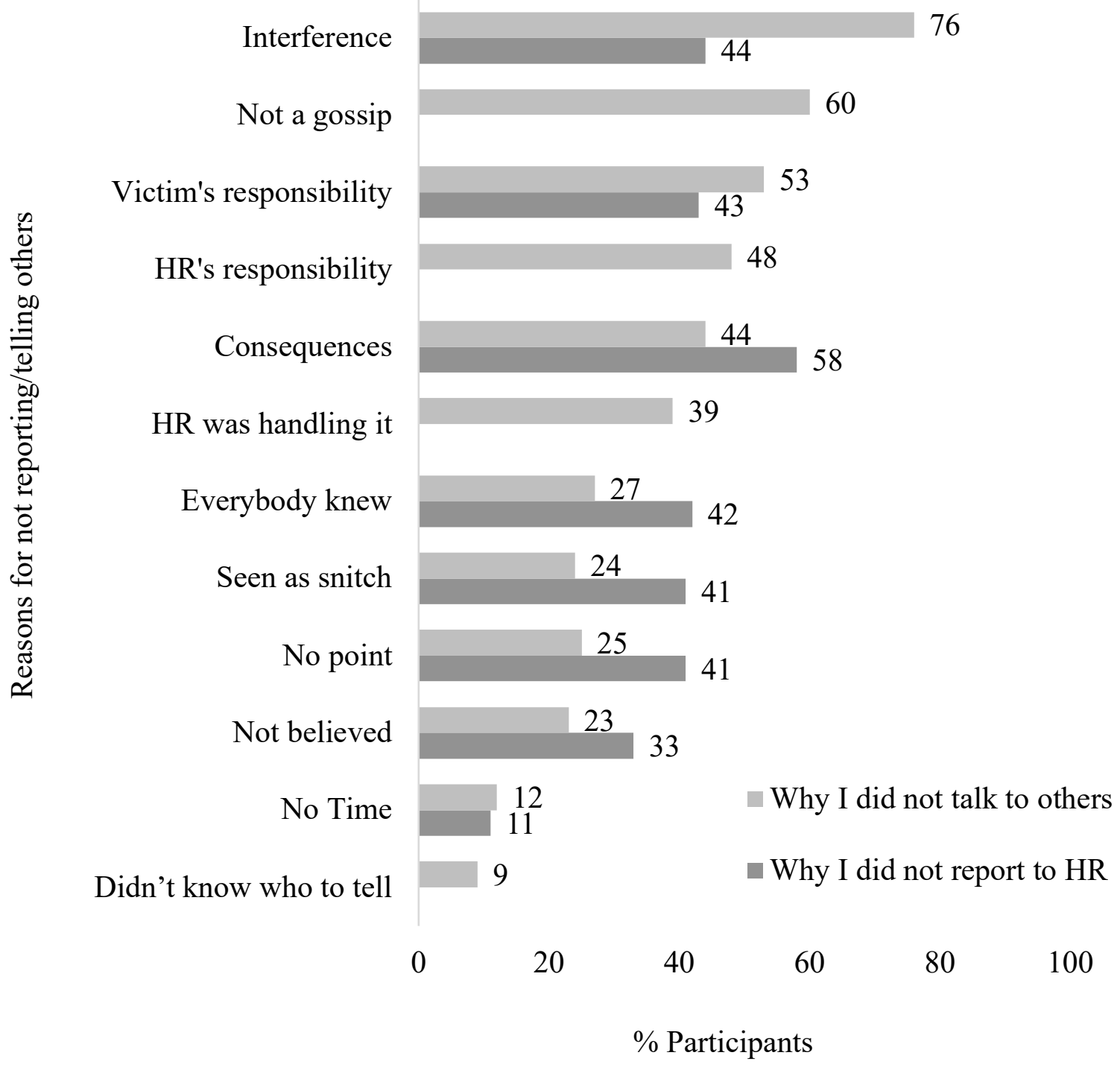

Figure 7. Comparison of barriers to reporting and barriers to telling colleagues

Inspection of figure 7 revealed that the most frequently selected items for not talking to colleagues were Because I did not want to interfere, I did not want to gossip, I thought it was the victim's responsibility, then HR should deal with it. This suggests that the difference (between talking to colleagues and reporting to HR) was largely driven by wanting to stay out of the victim's business (when discussing with colleagues) and fear of consequences (when reporting to $\mathrm{HR})$. 


\section{EVERYBODY KNOWS: WITNESSING WORKPLACE HARASSMENT}

The outcomes of discussing incident(s) to people in the workplace.

One of the main reasons that victims do not report workplace harassment is due to fear of the consequences, (Charlesworth, McDonald, \& Cerise, 2011), and these fears are often justified (Cortina \& Magley, 2003), so it was important to know whether fear of consequences is also justified in witnesses.

\section{Outcomes for witnesses: consequences of reporting to HR: Survey 3.}

We explored this in the following way. If participants had reported to HR, they were asked, "We are interested in knowing what happened when you told HR. How was your experience in the following ways?". Participants were given topics, such 'confidentiality', and response options such as:

HR did not keep what I told them confidential

HR kept what I told them confidential

I'm not sure if HR kept what I told them confidential

The same procedure was followed for each topic, presented in figure 8 . For these topics, 66 participants responded. 


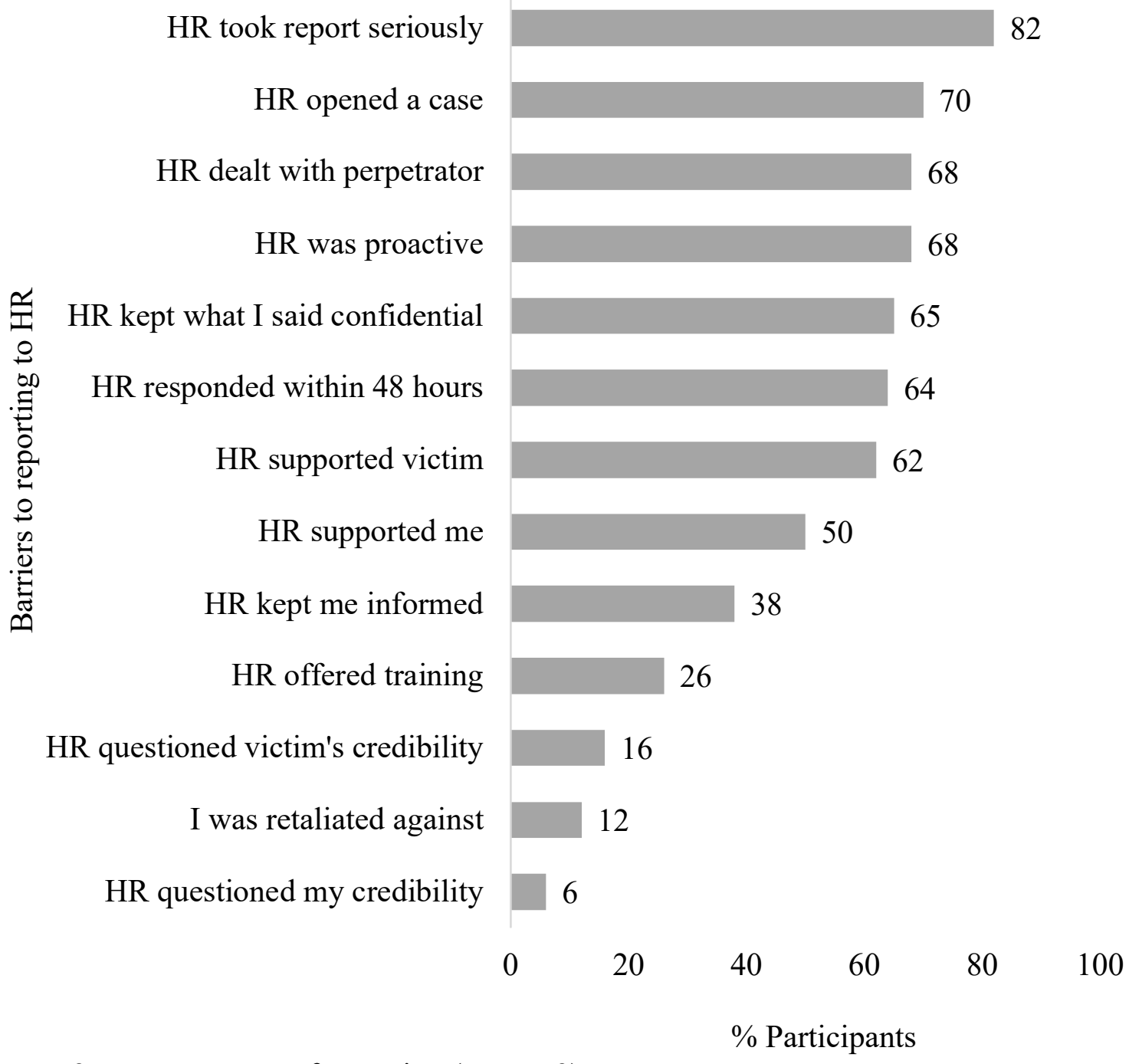

Figure 8. Consequences of reporting (survey 3).

Inspection of figure 8 revealed that the most frequently selected consequences of reporting were HR took the report seriously; HR opened a case; HR dealt with the perpetrator; and HR was proactive. Thus, HR often appeared to be responding well to reports when it came to victim and perpetrator procedures (as far as the participants were aware). However, it is worth considering that this might be because only those who felt they worked in supportive environments also reported the incidents to HR, and in most cases, they were justified in feeling this way. In cases where participants had chosen not to report, their decision might have been influenced by the perception that they would not have been 


\section{EVERYBODY KNOWS: WITNESSING WORKPLACE HARASSMENT}

supported for doing so, and the free text data suggests that this decision might have been justified in some cases. Indeed, one participant wrote "There have been numerous incidents reported to "HR" unfortunately the "HR" department has a relative to the individual and anytime a complaint is filed this person notifies the other and nothing is done about it...I personally watched a coworker lose their job because of a complaint made.".

HR did less well overall when it came to handling witnesses, as only half the participants felt supported by HR, just over a third were kept informed following their report, six percent responded that their credibility was questioned, and 12 percent responded that they were retaliated against following their report. Thus, witnesses are not always protected by HR when they speak up.

\section{Outcomes for witnesses: retrospective feelings about reporting decisions (pride and regret): Survey 3 .}

As witnesses experience negative consequences of workplace harassment (Ragins et al., 2017), it was also important to know whether decisions to discuss incidents were related to subsequent positive or negative feelings. Therefore, having responded either 'yes' or 'no' to the question "Did you make a formal report to the HR department?" they were asked two questions.

The first asked, "We are interested in whether you have any regrets about your reporting decisions when you witnessed the incident(s)." They had four options:

I do not regret what I did, but would probably do something different if I witnessed another incident 


\section{EVERYBODY KNOWS: WITNESSING WORKPLACE HARASSMENT}

I do not regret what I did, and would probably do the same thing if I witnessed another incident

I regret what I did, and would probably do something different if I witnessed another incident I regret what I did, but would probably do the same thing if I witnessed another incident

The $\chi^{2}$ statistic $\left(\chi^{2}(3)=21.03, p-<.001\right)$ showed a significant association between reporting decision and regret. The z-scores revealed that more people who reported to HR, also responded that they felt no regret and would do the same again $(p<.05)$, while fewer of those who reported to HR responded that they felt regret and would do something different if they witnessed another incident $(p<.05)$. No other comparisons were significant. Thus, participants who reported to HR were significantly less likely to experience regret and want to do something different in the future than those who did not report. The qualitative data showed that these feelings were sometimes long-lasting. One participant said, "Looking back, I now regret that."

The qualitative data also revealed that the presence or absence of regret centred around the consequences of their reporting decision. If there was an inadequate response to their report, witnesses that reported to HR tended to feel regret and/or would consider taking a different approach if they witnessed another incident in the future. One participant wrote "The managers are not going to do anything about the harassment. They see it every day and turn a blind eye to it." another wrote, "Altogether it was a negative experience. It caused me some sleepless night.", and another wrote "I would have offered more support to the victim in retrospect". In contrast, those that reported and had a positive experience tended to feel no regret. One participant wrote, "I was really respected in the office after everyone knew I didn't ignore something immoral.". 


\section{EVERYBODY KNOWS: WITNESSING WORKPLACE HARASSMENT}

The second question asked, "We are interested in whether you have any pride about your reporting decisions when you witnessed the incident(s). " They had four options:

I am proud of what I did, but would probably do something different if I witnessed another incident

I am proud of what I did, and would probably do the same thing if I witnessed another incident

I am not proud what I did, and would probably do something different if I witnessed another incident

I am not proud what I did, but would probably do the same thing if I witnessed another incident

The $\chi^{2}$ statistic $(\chi 2(3)=50.75, p<.001)$ showed a significant association between reporting decision and pride. The z-scores revealed that significantly fewer participants who had not reported to HR responded that they felt pride and would do the same again $(p<.001)$, while more of those who did report responded that they felt pride and would do the same again $(p<.001)$. Also, more participants who had not reported to HR responded that they felt no pride and would do something different in the future $(p<.001)$, while fewer of those who did report responded that they felt no pride and would do something different in the future $(p$ $<.001)$. Thus, participants who reported to HR were most likely to experience pride and want to do the same in the future than those who did not report. These feelings were sometimes powerful. For instance, one participant said, "I felt like a hero after the incident.".

The qualitative data also revealed that the presence or absence of pride centred around the consequences of their reporting decision. When the consequences were positive, participants that reported to HR tended either to feel pride and/or respond that they would do 


\section{EVERYBODY KNOWS: WITNESSING WORKPLACE HARASSMENT}

the same thing if they witnessed another incident in the future. One participant wrote, "Everyone including the victim thanked me".

If the consequences of reporting were negative, participants tended to feel pride but also respond that they would do something different if they witnessed another incident in the future. A participant wrote, "I ended up leaving and this reason had a bit to do with it. The fact that they did nothing and let the people continued to act the way they were was too much. I also had been treated badly".

Thus, while participants were significantly more likely to feel pride if they reported to HR and regret if they did not, the more nuanced qualitative data indicates that emotional responses are linked also to the consequences of reporting decisions.

\section{Indirect outcomes for victims: Permission seeking: Survey 3.}

Discussing witnessed events might compromise the victim's anonymity, they might not be desired or known about by the victim, and they have the potential to lead to victim retaliation. So, it was important to know whether witnesses were seeking permission to discuss incidents with people at work before doing so.

Therefore, in survey 3, participants $(\mathrm{n}=369)$ were asked; “Did you seek permission from the victim to report to HR about what you had witnessed?" and, "Did you seek permission from the victim to tell other colleagues what you had witnessed?". Of those who had discussed incidents with someone in the workplace, 70 percent indicated that they had not sought permission before discussing them, and Binomial tests revealed that the proportion of witnesses that did not seek permission to report to HR before doing so (64 percent) was 
significantly greater than those who did seek permission $(p=.03)$, and those that did not seek permission to tell colleagues ( 88 percent) was significantly greater than those who did seek permission $(p<.001)$. Thus, most witnesses discussed incidents in the workplace without seeking permission from the victim first, and that this was overwhelmingly the case when it came to discussing with colleagues. This effectively compromised the anonymity of victims without their consent and/or knowledge. Indeed, one participant wrote, "I felt the victim would have told me not to report it so I felt it was my duty to report it without their knowledge.". Another wrote, "if somehow they said please don't report it, I would have reported anyway because the offender needed to be stopped.” These quotes highlight the need for workplaces to encourage witnesses to seek the victim's permission before discussing an incident in the workplace.

\section{What witnesses want their workplaces to do about witness reporting: Survey 3.}

Reporting mechanisms seem to be failing victims of workplace harassment and discrimination as they are seldom used (EEOC, 2016), so we predicted that this would also be the case when it came to witnesses. Therefore, we asked participants to what they wanted workplaces to do to improve witness reporting in a novel Harassment Reporting Model (HRM) (Appendix 1), as they were well placed to offer insight into what is needed to make the process easier or more accessible. For each item, participants were asked to respond in one of four ways, and responses were coded from 1-4, with 1 being the most negative opinion of the item and 4 being the most positive. The responses and coding scores are below.

HR in my workplace already does this. It has NOT made reporting better (coding score =1) HR in my workplace does not do this. It would NOT make reporting better (coding score = 2) 


\section{EVERYBODY KNOWS: WITNESSING WORKPLACE HARASSMENT}

HR in my workplace does not do this. It would make reporting better (coding score = 3)

HR in my workplace already does this, and it has made reporting better (coding score $=4$ )

An exploratory factor analysis was conducted on the 10 items with a promax rotation. One item (Q7. Allow witnesses to report via a 3rd party) was omitted for not loading and the analysis was run again. The Kaiser-Mayer-Olkin measure verified the sampling adequacy for the analysis, $\mathrm{KMO}=.88$ ('meritorious' according to Hutcheson \& Sofroniou, 1999), and all $\mathrm{KMO}$ values for individual items were greater than .82 , which is well above the acceptable limit of .5 (Field, 2013). An initial analysis was run to obtain eigenvalues for each factor in the data. Two factors had eigenvalues over Kaiser's criterion of 1 and in combination explained $60.04 \%$ of the variance. The scree plot justified retaining two factors and RMSEA (.04) and TLI (.98) both indicated that the model fit was good. Table 4 shows the factor loading after rotation and includes the reliability analyses for both factors. The items suggest that factor 1 represents items that motivate and empower witnesses to report, and included: Allow witnesses to stay anonymous; Give people choices about how they want to report (e.g. online, to a human, to a hotline); Get HR to encourage witnesses to report; and Make it easier for witnesses to report. Factor 2 represents items related to a creative and proactive $H R$, and included: Allow witnesses to report via an automated online system; Remind witnesses regularly how to report; Create targeted training programmes (e.g. people skills for managers); Provide harassment hotlines; and Remove conflicts of interest (e.g. person handling harassment case related to the perpetrator). See Appendix 2 for correlations. 
Table 4. Summary of exploratory factor analyses results for the WHM $(n=177)$ Motivate and empower witnesses Creative and proactive HR

\begin{tabular}{lrr}
\hline Q1 & $\mathbf{0 . 8 7 6}$ & -0.109 \\
Q2 & $\mathbf{0 . 8 7 2}$ & -0.03 \\
Q3 & $\mathbf{0 . 6 9 1}$ & 0.174 \\
Q4 & $\mathbf{0 . 8 4 2}$ & 0.007 \\
Q5 & 0.331 & $\mathbf{0 . 4 7 1}$ \\
Q6 & 0.107 & $\mathbf{0 . 6 6}$ \\
Q8 & 0.097 & $\mathbf{0 . 5 9 7}$ \\
Q9 & -0.273 & $\mathbf{0 . 9 5}$ \\
Q10 & 0.187 & $\mathbf{0 . 5 8 1}$ \\
\hline Eigenvalues & 4.33 & 1.08 \\
\% of variance & 48.07 & 11.96 \\
$a$ & 0.85 & 0.75 \\
\hline
\end{tabular}

Figure 9 revealed for items that motivated and empowered witnesses to report (range of scores 4-16), the greatest proportion of participants (25.4\%) gave a combined score of 11 , indicating that participants had largely responded that their HR did not have the items in place, but they thought that they would help to improve reporting, while the next greatest proportion of participants (24.9\%) gave the maximum score (16), indicating that their workplaces already had each item in place and they had improved reporting. When it came to items that reflected creative and proactive HR (the range of scores was 5-20), the two most commons scores were $15(23.7 \%)$ and $16(13.6 \%)$, indicating that participants had largely responded that their HR did not have the items in place, but they thought that they would help to improve reporting. Only 7.3 percent gave the maximum score (20). Thus, workplaces appear to be better at motivating and empowering witnesses to report than thinking of 
creative and proactive ways of improving reporting, although the combined results show that there is room for improvement in both factors.

\section{0}

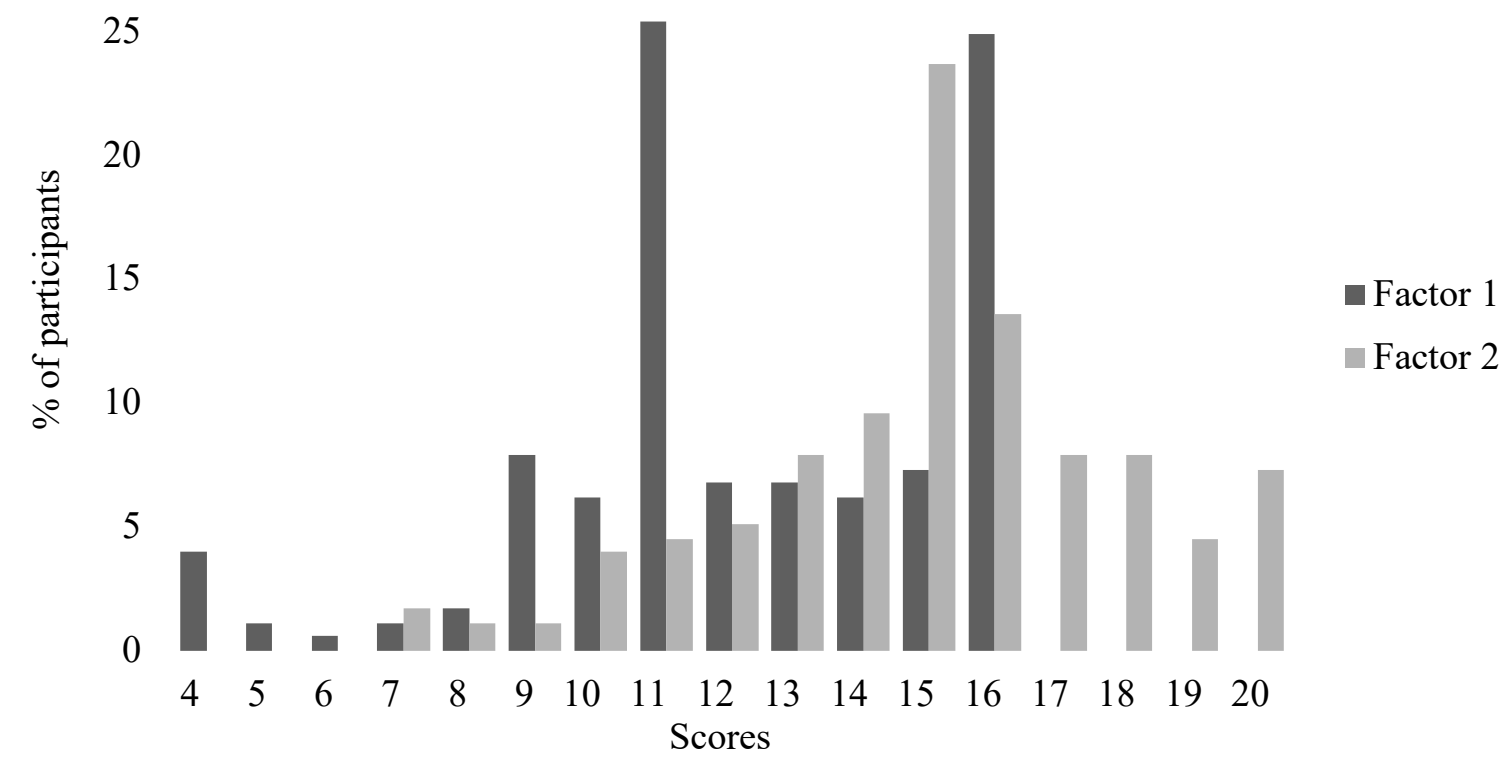

Figure 9. Percentages of sum scores for both factors. Possible scores for factor 1 (motivating and empowering witnesses) ranged between 4 and 16, as it contained four items. Possible scores for factor 2 (creative and proactive HR) ranged between 5 and 20, as it contained five items.

\section{Discussion}

The MeToo movement has shed light on the prevalence of sexual harassment in the workplace (MeToo, n.d.), which is echoed by other forms of workplace harassment (e.g. EEOC, 2016; Shannon, Rospenda, Richman \& Minich, 2009). The main goals of the present research were therefore to see whether barriers to and/or consequences of witnessing workplace harassment were similar or different between victims and witnesses; whether witnesses to workplace harassment could or should be encouraged to support victims by 


\section{EVERYBODY KNOWS: WITNESSING WORKPLACE HARASSMENT}

reporting on their behalf or by submitting evidentiary support; and whether this might also benefit workplace climates and witnesses themselves. We also explored practical solutions to improving witness reporting.

The first aim was to ask how common it was for witnesses to report incidents, and we found that 77 percent of witnesses in the current survey chose not to report to HR, which is significantly larger than the EEOC (2016) figure of 70 percent. It is important to note that the EEOC report refers to victim reporting (to someone of authority in the workplace), whereas the present research refers to witness reporting (to HR), and it is worth noting that research conducted since the MeToo movement indicates that this figure is probably conservative. For instance, McCann, Tomaskovic-Devey and Badgett (2018) found that as many as 99.8 percent of sexual harassment incidences are never reported. However, using the EEOC figure as a starting point, our results support the idea that for every victim that does not report a witnessed incident, there is at least one witness who has also failed to report. This finding was not unexpected, as a common assumption is that it is the victim's responsibility to report incidences, which overlooks the supportive role that witnesses could play. The responsibility of victims to report is, in turn, supported by the present research, where 43 percent of participants selected victim responsibility as a reason for not reporting to $\mathrm{HR}$, and 10 percent responded that witness reporting was either not an option in their workplace or was actively discouraged.

It was also important to understand whether witness underreporting was related to witnesses not wishing to tell HR, specifically, or whether they also did not tell other people about the incidents. The results revealed that the proportion of witnesses who reported to HR was significantly smaller than those who told other colleagues (witnesses predominantly told 


\section{EVERYBODY KNOWS: WITNESSING WORKPLACE HARASSMENT}

team members), and this was significantly smaller than the proportion who told friends or family. This suggests, first, that incidents of workplace harassment were important enough for most witnesses to discuss with someone (Cortina \& Berdahl, 2008). It also suggests that decisions to discuss incidents could be driven by perceptions of power (in)equality, (mis)trust or (un)familiarity, and/or are driven by the need to confide rather than to start a formal process, although it would be worth exploring this further in future research.

The second aim was to examine whether there are incentives for witnesses to report, or whether they face barriers, as victims do. The incentives that witnesses gave for reporting to HR (or speaking to colleagues) centred around wanting to stop the perpetrator, dislike of unfair treatment, and supporting the victim, indicating that workplace fairness and justice were important reasons for discussing incidents at work. Also, the data supported three notions: "everybody knows" (except HR); witnesses (not just victims) are afraid of the consequences; and witnesses (not just victims) are affected by workplace harassment, supporting Ragins et al. (2017). Indeed, one person wrote "That ultimately led to some severe depression and other health issues that are still ongoing years later. I just didn't know how to deal with it that well at that time.". The least common incentive to report was "The victim asked me to,". This indicates that victims fail to think of witnesses as reporting resources, and that witnesses and victims do not communicate effectively about reporting options (discussed further below).

The most common barrier to reporting to HR was fear of consequences, which mirrors that of victims (e.g. Charlesworth et al., 2011), demonstrating that the greatest need for workplaces in tackling the underreporting of workplace harassment is to reassure all employees that they will be protected and supported if they report. This was followed by not 


\section{EVERYBODY KNOWS: WITNESSING WORKPLACE HARASSMENT}

wanting to interfere; it was the victim's responsibility to report to HR; everybody knew already; there was no point; and not wanting to be seen as a snitch. Perceptions around not wanting to interfere and that it was the victim's responsibility to report, mirrored the debate in the House of Commons (2018, p 13), where it was discussed that current reporting processes place an unreasonable burden on victims to tackle harassment alone. Witnesses also did not report due to powerful people or HR being involved; because there was no witness reporting mechanism; or because witnesses were not allowed to report. Interestingly, "Everybody knows" was cited as both an incentive for reporting and as a barrier to reporting, supporting both the bystander literature that when an incident is witnessed (or known about) by several people, bystanders will not intervene (Latané \& Darley, 1970), and that a shared identity can help to encourage bystander intervention (Levine \& Manning, 2013). Therefore, it would be worth workplaces attempting to reframe the knowledge about incidents of harassment as an incentive to report rather than as a reason not to, by creating a shared identity of solidarity. Indeed, the most common reasons for reporting centred around things that would benefit either the victim or the workplace climate in general, while the least common reasons centred around things that would benefit the witnesses themselves. So, this altruism could be channelled into witness reporting. Possible links between shared identities, altruism, and reporting warrant further investigation.

When deciding not to talk to colleagues, participants most frequently selected that they did not want to interfere; they did not want to gossip; and it was the victim's responsibility. Thus, reasons participants gave for not discussing incidents with colleagues appeared to be mainly driven by perceived responsibility of, or respect to, the victim and their privacy. Therefore, it might be worth educating all employees that discussing incidents with 


\section{EVERYBODY KNOWS: WITNESSING WORKPLACE HARASSMENT}

other colleagues (without the victims' knowledge) undermines the victims' control over whether or not to discuss the incident in the workplace. Overall, while witnesses seem keener to discuss incidents with colleagues, lack of trust in HR and the lack of a dedicated reporting process for witnesses appear to be hampering efforts to encourage formal reporting, as is the notion 'everybody knows'. It would be worth exploring ways to channel witnesses desire to discuss what they have witnesses into a formal report, in future research.

The matter of witness reporting raises concerns about victim anonymity, which is important in reporting procedures (Buchanan et al., 2014; EHRC, 2018). To clarify whether witnesses took this into account, participants were asked whether they had sought permission from the victim to discuss the incidents with others in the workplace. The results showed that 70 percent of witnesses did not ask for permission, and this figure was particularly high when it came to discussing incidents with colleagues, compared to reporting them to HR. The results indicate that information is spread round the workplace, usually without the victim's permission or consent, compromising the victim's anonymity as well as risking social contagion (Christakis \& Fowler, 2013). It is worth noting, however, that in survey 3, 20 percent of participants said one of the people they had chosen to talk to was the victim. The survey did not ask whether some were doing so to seek permission from the victim and/or whether permission had been granted. If not, it would be worth exploring whether these discussions could be opportunities to do so.

If a well-meaning witness talks about an incident without protecting the victim's anonymity, this may lead to secondary victimisation that the victim had been attempting to avoid by not reporting themselves. Without permission, witnesses also risk betraying trust between colleagues, adding to psychological harm (e.g., Elangovan \& Shapiro, 1982), 
particularly if a witness and victim work closely together. It can also damage the workplace culture, either by making the victim feel more isolated (Herbenick et al., 2019) or powerless, particularly if nothing is done to help them; or by making more people aware of the situation, so that toxicity and fear is spread further in a social contagion effect (Barsade, 2002;

Christakis \& Fowler, 2013). Thus, it is worth witnesses trying to get permission before sharing details of incidents with others.

The third aim was to understand the consequences of witnesses' reporting decisions. The most common responses were that HR opened a case, and took the report seriously, suggesting that witness reports are most likely to be responded to by HR in a professional manner. However, in the present research, 'professionalism' appeared to be more about being seen to be proactive rather than accounting for the needs of witnesses, who were not always adequately supported, informed or protected. Indeed, while lack of belief in the witness and/or retaliation were the least common consequences, fear of them were justified in some cases. However, it is worth noting that we could only explore the responses of participants who had opted to report, and these participants might have only chosen to do so, as they believed that their workplace would support them in doing so. Thus, the data is useful for comparing different types of HR responses within the population in this survey, rather than for extrapolating to predicted responses of HR professionals in all settings.

Nevertheless, in our data, it was found that participants who reported to HR were significantly less likely to experience regret than those who did not report, while those who reported to HR were significantly more likely to experience pride than those who did not report. The qualitative data also revealed that pride and regret were related, in particular, to the consequences of making a report. Those who experienced positive consequences more 


\section{EVERYBODY KNOWS: WITNESSING WORKPLACE HARASSMENT}

commonly described pride, while those who experienced negative consequences more commonly described regret. Therefore, witnesses' reporting decisions can have an impact on their feelings of regret or pride, which is likely also to be related to the consequences of their reporting decision, and is sometimes powerful or long-lasting. Given that witnesses are negatively affected by workplace harassment (Ragins et al., 2017), any mechanism that encourages reporting and supports witnesses after making a report has the potential to mitigate the negative affects rather than exacerbate them.

While the current research highlights missed opportunities to empower employees by encouraging witnesses to support victims after workplace harassment, it also presents workplaces with an opportunity to take action. Therefore, the final aim was to inspect witnesses' insights into reporting processes, to see how the processes could be improved. We asked participants to tell us the approaches that their HR already took that they felt had (not) improved witness reporting, as well as approaches that their HR did not take that they felt would (not) improve it. We used their responses to create a preliminary model of harassment reporting, the HRM, with factor analysis. This revealed that two harassment reporting factors. These were motivating and empowering witnesses, and a creative and proactive $H R$. The first factor included the following items: Allow witnesses to stay anonymous, which is also recommended by the EHRC (2018) for the victims of harassment; Give people choices about how they want to report (e.g. online, to a human, to a hotline), reflecting issues with reporting sexual harassment in organisations with a strict chain of command, such as the Armed Forces (Markson, 2018); Get HR to encourage witnesses to report; and Make it easier for witnesses to report. These last two items could potentially reduce the burden on victims to 


\section{EVERYBODY KNOWS: WITNESSING WORKPLACE HARASSMENT}

report alone, identified as an issue by the House of Commons (2018, p 13). About a quarter of workplaces already had each of these items in place successfully.

The second factor included: Allow witnesses to report via an automated online system, which supports the recommendations of the EHRC (2018) for increasing the likelihood of reporting and decreasing incidents of harassment in the first place; Remind witnesses regularly how to report; Create targeted training programmes, such as the benefits of reporting (Paull et al, 2010, Rayner \& Bowes-Sperry, 2008); Provide harassment hotlines $^{7}$; and Remove conflicts of interest (e.g. person handling harassment case related to the perpetrator). About a third of participants responded that their HR did not have the items in place, but they thought that they would help to improve reporting, while only 7.3 percent responded that their HR had these valued approaches in place. Thus, while the pattern of responses for each factor was different, there is room for improvement in reporting mechanisms for witnesses overall.

The HRM is a tentative first step to understanding possible solutions to witness reporting, and our data suggests that witnesses are telling workplaces that they need anonymous, easy to use, online reporting mechanisms, for both victims and witnesses ${ }^{8}$. These

${ }^{7}$ Note: in some cases, qualitative data revealed that some internal harassment hotlines are not trusted by employees. Therefore, while the item Allow witnesses to report via a $3 \mathrm{rd}$ party was excluded from the model for not loading, it may be worth exploring the contribution of third party mechanisms in future research.

${ }^{8}$ Note: while anonymity will necessarily limit the scope of some investigations, it is also the most likely means to finding out about inappropriate behaviour. It is also worth noting that while third party reporting was not the most popular suggestion, providing third party systems can provide anonymity more effectively than integrated systems, and also serve to give employees confidence that reporting will be anonymous. 


\section{EVERYBODY KNOWS: WITNESSING WORKPLACE HARASSMENT}

mechanisms have been shown to effective in mental health (Vaidyam, Wisniewski, \& Halamka, 2019) and for emotional disclosure (Ho, Hancock, \& Miner, 2018), and are readily available (e.g. Talk to Spot, n.d.; Vault, n.d.). Also, similar mechanisms have been suggested by previous research to help encourage victim reporting of sexual harassment and to reduce incidences in the first place (Buchanan et al., 2014; EHRC, 2018). Therefore, they should be effective when it comes to witness reporting (of all forms of workplace harassment). For workplaces that cannot introduce integrated cyber mechanisms, having reporting choices (different pathways to report); actively encouraging witnesses to report (and supporting them during the process); targeted training programmes, such as teaching the benefits of reporting (Paull et al, 2010, Rayner \& Bowes-Sperry, 2008); or removing conflicts of interest (which can be partially achieved by providing reporting choices/pathways) could be other viable options. However, more research into refining the model is needed in future research.

Based on the present results, workplace harassment is still a pressing issue, and more is required to make workplaces healthier (see Goncharenko, 2019, for a guide). However, our research suggests that organizations can minimise isolated suffering in silence, by building workplaces of solidarity, support, and speaking up (rather than workplaces of monitoring or policing). They can achieve this by actively encouraging witnesses to report harassment as well as victims, and by guiding witnesses to seek permission from the victim before talking about incidents - so that victims can maintain control over their anonymity, and feel less isolated (Herbenick et al., 2019). Witnesses can also be educated about the benefits of reporting (Paull et al, 2010, Rayner \& Bowes-Sperry, 2008), and be reassured that they will be supported rather than victimised for doing so. To achieve this, organisations are 
encouraged to give employees flexible reporting systems with multiple pathways that bypass any conflicts of interest and power imbalances.

The message is therefore positive. While this research was exploratory, it indicated that by redirecting people's need to discuss what they have seen into an appropriate reporting channel or mechanism, positive change could be possible. By introducing this, witnesses may be mobilised to take action when they encounter inappropriate incidences, empowering themselves to be a force for good in their workplace, while also protecting themselves. They remain a largely untapped resource in tackling workplace harassment, but should be seen as allies for victims (offering support and solidarity when needed), allies for co-workers (reinforcing a shared identity of empowerment in the face of inappropriate behaviour), and allies for employers (helping them to learn about incidents that would otherwise go unreported), and this should improve their own emotional response to the incident. Thus, engaging witnesses has the potential to help organizations restore the inclusivity and health of their workplaces by preventing social contagion and building a positive shared identity of social solidarity. 


\section{Considerations:}

While it is difficult for small organisations to have the kind of reporting options discussed in this paper, especially when it comes to digital approaches, the considerations below might be of use for improving or maintaining healthy workplace climates.

1. Workplaces should encourage witnesses to report workplace harassment, to protect victims and witnesses from the negative effects of staying silent, and so that $\mathrm{HR}$ professionals are aware of and able to act upon the situation.

2. Workplaces should inform employees that witness reporting will be encouraged, taken seriously, and acted upon, in an attempt to encourage solidarity with victims; as an acknowledgment that working in a harassing environment contributes to an unhealthy environment; and to discourage workplace harassment in the first place.

3. Workplaces should seek to reassure employees that they will support, inform, update, and protect witnesses during the process of making a report, as valued employees who have acted in the interest of the victim and the workplace as a whole, rather than as interfering troublemakers. This should increase trust in the process and encourage witnesses to come forward.

4. Workplaces should educate employees about the need to seek permission from victims before discussing incidents in their workplace, to give victims control over their own anonymity; to ensure that victims are not suffering in isolation; to minimise the likelihood of secondary retaliation; and to minimise the likelihood of negative social contagion.

5. Workplaces should extend victim reporting processes to include witnesses. These should be readily accessible (e.g. clear instructions in induction packs and/or reporting apps on desktop computers); have different reporting pathways (e.g. choices about who handles a case); have anonymous options (e.g. choosing which professional sees which identifying information); and have automated online reporting systems (to bypass issues related to anonymity and/or conflicts of interest). 


\section{References}

Ashburn-Nardo, L., Blanchar, J. C., Petersson, J., Morris, K. A., \& Goodwin, S. A. (2014). Do You Say Something When It's Your Boss? The role of perpetrator power in prejudice confrontation: Perpetrator power and prejudice confrontation. Journal of Social Issues, 70, 615-636. https://doi.org/10.1111/josi.12082

AHRC, (2008) The Arts and Humanities Research Council Annual Report and Accounts 2007-2008. Retrieved from https://assets.publishing.service.gov.uk/government/uploads/system/uploads/attachme nt_data/file/248449/0881.pdf

All Together Now (n.d.) retrieved 2nd September 2019, from https://alltogethernow.org.au

Bandura, A. 1986. Social foundations of thought and action: A social cognitive theory. Englewood Cliffs, NJ: Prentice- Hall.

Banyard, V. L., Moynihan, M. M., \& Plante, E. G. (2007). Sexual violence prevention through bystander education: An experimental evaluation. Journal of Community Psychology, 35, 463-481. https://doi.org/10.1002/jcop.20159

Barsade, S. G. (2002). The ripple effect: Emotional contagion and its influence on group behaviour. Administrative science quarterly, 47(4), 644-675

Bergman, M. E., \& Henning, J. B. (2008). Sex and ethnicity as moderators in the sexual harassment phenomenon: A revision and test of Fitzgerald et al. (1994). Journal of Occupational Health Psychology, 13, 152-167

Bowes-Sperry, L., \& O’Leary-Kelly, A. M. (2005). To act or not to act: The dilemma faced by sexual harassment observers. Academy of Management Review, 30(2), 288-306.

Bowling, N. A., \& Beehr, T. A. (2006). Workplace harassment from the victim's perspective: A theoretical model and meta-analysis. Journal of Applied Psychology, 91(5), 9981012. 


\section{EVERYBODY KNOWS: WITNESSING WORKPLACE HARASSMENT}

Branch, S., Ramsay, S., \& Barker, M. (2013). Workplace bullying, mobbing and general harassment: A Review: Workplace bullying: A review. International Journal of Management Reviews, 15(3), 280-299.

Brandtzaeg, P. B., \& Følstad, A. (2017, November). Why people use chatbots. In International Conference on Internet Science (pp. 377-392). Springer, Cham. https://doi.org/10.1007/978-3-319-70284-1_30

Brodsky, C. M. (1976). The harassed worker. MA. Toronto: Lexington Books, D.C.

Buchanan, N. T., \& Fitzgerald, L. F. (2008). Effects of racial and sexual harassment on work and the psychological well-being of African American women. Journal of Occupational Health Psychology, 13(2), 137-151.

Buchanan, N. T., Settles, I. H., Hall, A. T., \& O’Connor, R. C. (2014). A review of organizational strategies for reducing sexual harassment: Insights from the US military. Journal of Social Issues, 70(4), 687-702

Burgess, D., Lee, R., Tran, A., \& van Ryn, M. (2008). Effects of perceived discrimination on mental health and mental health services utilization among gay, lesbian, bisexual and transgender persons. Journal of LGBT Health Research, 3(4), 1-14.

Cortina L.M. and Bergdahl, J.L. (2008) Sexual harassment in organisations: A decade in of research in review. Retrieved 29th July 2019, from https://books.google.co.uk/books?hl=en\&lr=\&id=q5LTTMglfJ8C\&oi=fnd\&pg=PA46 $9 \& \mathrm{dq}=$ Cortina $+\% 26+$ Berdahl\&ots=BVhvIYMuto\&sig=axqPG0Iv1lz8_g4XizPuJaj3 Bos\# $\mathrm{v}=$ onepage $\& \mathrm{q}=$ Cortina $\% 20 \% 26 \% 20$ Berdahl $\& \mathrm{f}=$ false

Cortina, L. M., \& Magley, V. J. (2003). Raising voice, risking retaliation: Events following interpersonal mistreatment in the workplace. Journal of Occupational Health Psychology, 8(4), 247-265. https://doi.org/10.1037/1076-8998.8.4.247

Charlesworth, S., McDonald, P., \& Cerise, S. (2011). Naming and claiming workplace sexual harassment in Australia. Australian Journal of Social Issues, 46(2), 141-161. 


\section{EVERYBODY KNOWS: WITNESSING WORKPLACE HARASSMENT}

Christakis, N. A., \& Fowler, J. H. (2013). Social contagion theory: Examining dynamic social networks and human behaviour. Statistics in Medicine, 32(4), 556-577

D'Cruz, P., \& Noronha, E. (2011). The limits to workplace friendship: Managerialist HRM and bystander behaviour in the context of workplace bullying. Employee Relations, 33(3), 269-288.

Deitch, E. A., Barsky, A., Butz, R. M., Chan, S., Brief, A. P., \& Bradley, J. C. (2003). Subtle yet significant: The existence and impact of everyday racial discrimination in the workplace. Human Relations, 56(11), 1299-1324.

Diversity Watch (n.d.) retrieved 2nd September 2019, from http://diversitywatch.uk

Dougherty, D. S. (2000). Women's discursive construction of a sexual harassment paradox. Communication Quarterly, 48(3), Q6.

EEOC (2016), Select task force on the study of harassment in the workplace, retrieved 29th July, 2019, from https://www.eeoc.gov/eeoc/task_force/harassment/report.cfm\#_Toc453686302

EHRC (2018), retrieved 4th May, from https://www.equalityhumanrights.com/en/publication-download/turning-tablesending-sexual-harassment-work

Elangovan, A. R., \& Shapiro, D. L. (1998). Betrayal of trust in organizations. Academy of Management Review, 23(3), 547-566

Field, A.P. (2013). Discovering statistics using IBM SPSS Statistics: And sex and drugs and rock ' $n$ ' roll (4th ed.). London: Sage.

Finn, J. (2004). A survey of online harassment at a university campus. Journal of Interpersonal Violence, 19(4), 468-483. https://doi.org/10.1177/0886260503262083

Fitzgerald, L. F., \& Shullman, S. L. (1993). Sexual harassment: A research analysis and agenda for the 1990s. Journal of Vocational Behavior, 42(1), 5-27. 


\section{EVERYBODY KNOWS: WITNESSING WORKPLACE HARASSMENT}

Goncharenko (2019) \#MeToo: A journey towards a harassment-free workplace. Retrieved, $10^{\text {th }}$ Novemebr, 2019, from

http://sro.sussex.ac.uk/id/eprint/87960/1/Goncharenko\%20et\%20al_MeToo_best\%20 practice\%20guide_2019.pdf

Good, J. J., Moss-Racusin, C. A., \& Sanchez, D. T. (2012). When do we confront?

Perceptions of costs and benefits predict confronting discrimination on behalf of the self and others. Psychology of Women Quarterly, 36(2), 210-226.

Harrison, J., Grant, J., \& Herman, J.L. (2012). A gender not listed here: Genderqueers, gender rebels, and otherwise in the National Transgender Discrimination Survey. Los Angeles, University of California.

Herbenick, D., van Anders, S. M., Brotto, L. A., Chivers, M. L., Jawed-Wessel, S., \& Galarza, J. (2019). Sexual harassment in the field of sexuality research. Archives of sexual behavior, 48(4), 997-1006.

Ho, A., Hancock, J., \& Miner, A. S. (2018). Psychological, relational, and emotional effects of self-disclosure after conversations with a chatbot. Journal of Communication, 68(4), 712-733.

House of Commons (2018) Sexual harassment in the workplace, retrieved $16^{\text {th }}$ March, 2020 from https://publications.parliament.uk/pa/cm201719/cmselect/cmwomeq/725/725.pdf

Hulin, C. L., Fitzgerald, L. F, \& Drasgow, F. 1996. Organizational influences on sexual harassment. In M. S. Stockdale (Ed.), Sexual harassment in the workplace: Perspectives, frontiers, and response strategies. 127-150. Thousand Oaks, CA: Sage.

Hutcheson G., \& Sofroniou N., (1999). The multivariate social scientist. London: Sage.

.iHollaback (n.d.) retrieved 2nd September 2019, from https://www.ihollaback.org 


\section{EVERYBODY KNOWS: WITNESSING WORKPLACE HARASSMENT}

Ilies, R., Hauserman, N., Schwochau, S., \& Stibal, J. (2003). Reported incidence rates of work-related sexual harassment in the United States: using meta-analysis to explain reported rate disparities. Personnel Psychology, 56(3), 607-631.

Keashly, L., \& Jagatic, K. (2000, August). The nature, extent, and impact of emotional abuse in the workplace: Results of a statewide survey. In Presentado en el Annual Meeting of the Academy of Management, Toronto, Ontario, Canada.

Krieger, N., Chen, J. T., Waterman, P. D., Hartman, C., Stoddard, A. M., Quinn, M. M., ... Barbeau, E. M. (2008). The inverse hazard law: Blood pressure, sexual harassment, racial discrimination, workplace abuse and occupational exposures in US low-income black, white and Latino workers. Social Science \& Medicine, 67(12), 1970-1981.

Krieger, N., Smith, K., Naishadham, D., Hartman, C., \& Barbeau, E. M. (2005). Experiences of discrimination: Validity and reliability of a self-report measure for population health research on racism and health. Social Science \& Medicine, 61(7), 1576-1596.

Konrad, A. M., Yang, Y., \& Maurer, C. C. (2016). Antecedents and outcomes of diversity and equality management systems: an integrated institutional agency and strategic human resource management approach. Human Resource Management, 55, 83-107.

Lapierre, L. M., Spector, P. E., \& Leck, J. D. (2005). Sexual versus nonsexual workplace aggression and victims' overall job satisfaction: A meta-analysis. Journal of Occupational Health Psychology, 10(2), 155-169.

Latané, B., \& Darley, J. M. (1970). The unresponsive bystander: Why doesn't he help?. Appleton-Century-Crofts.

Lee, J. Y., Heilmann, S. G., \& Near, J. P. (2004). Blowing the whistle on sexual harassment: Test of a model of predictors and outcomes. Human Relations, 57(3), 297-322.

Levine, M., \& Manning, R. (2013). Social identity, group processes, and helping in emergencies. European Review of Social Psychology, 24(1), 225-251. 
Lim, S., \& Cortina, L. M. (2005). Interpersonal mistreatment in the workplace: The interface and impact of general incivility and sexual harassment. Journal of Applied Psychology, 90(3), 483-496.

Markson, H. (2018) Sexual Harassment Report, retrieved, $16^{\text {th }}$ March 2020, from https://assets.publishing.service.gov.uk/government/uploads/system/uploads/attachme nt data/file/736177/20180821_Sexual_harassment_report 2018 OS.PDF

Marsh, J., Patel, S., Gelaye, B., Goshu, M., Worku, A., Williams, M. A., \& Berhane, Y. (2009). Prevalence of workplace abuse and sexual harassment among female faculty and staff. Journal of Occupational Health, 51(4), 314-322.

McCann, C., Tomaskovic-Devey, D., \& Badgett, L. (2018). Employers' Responses to Sexual Harassment. Available at SSRN 3407960.

MeToo (n.d.). Retrieved $10^{\text {th }}$ January 2020, from https://metoomvmt.org

Miceli, M. P., \& Near, J. P. 1988. Individual and situational correlates of whistle-blowing. Personnel Psychology, 41: 267-282.

Minnotte, K. L. (2012). Perceived discrimination and work-to-life conflict among workers in the United States. Sociological Quarterly, 53(2), 188-210.

MSNBC, (2014, July). Report: Sexual harassment rampant in the restaurant industry. Retrieved from http://www.msnbc.com/msnbc/report-sexual-harassment-rampant-therestaurant industry

Neall, A. M., \& Tuckey, M. R. (2014). A methodological review of research on the antecedents and consequences of workplace harassment. Journal of Occupational and Organizational Psychology, 87(2), 225-257.

Near, J. P., Rehg, M. T., Van Scotter, J. R., \& Miceli, M. P. (2004). Does type of wrongdoing affect the whistle-blowing process? Business Ethics Quarterly, 14(2), 219-242. 


\section{EVERYBODY KNOWS: WITNESSING WORKPLACE HARASSMENT}

Nielsen, M. B., Glasø, L., \& Einarsen, S. (2017). Exposure to workplace harassment and the Five Factor Model of personality: A meta-analysis. Personality and Individual Differences, 104, 195-206. https://doi.org/10.1016/j.paid.2016.08.015

Paull, M., Omari, M. and Standen, P. (2010), "Keep your head down and your mouth shut: bystanders in workplace bullying”. In the 7th International Conference on Workplace Bullying and Harassment, Cardiff.

Positly (n.d.) retrieved 2nd September 2019, from https://www.positly.com

Potter, S. J., Fountain, K. G. and Stapleton, J. (2012) 'Addressing sexual and relationship violence in the LGBT community using a bystander framework', Harvard Review of Psychiatry, 20(4), pp. 201-208. doi: 10.3109/10673229.2012.712838.

Pregnant then Screwed (n.d.) retrieved 2nd September 2019, from http://pregnantthenscrewed.com

Qualtrics (n.d.) retrieved 2nd September 2019, from https://www.qualtrics.com/uk/lp/surveys/?utm_source=google\&utm_medium=ppc\&u tm_campaign $=\mathrm{uk}+$ brand\&campaignid $=8732303957 \&$ utm_content $=\&$ adgroupid $=872$ 50111119\&utm_keyword $=$ qualtrics\&utm_term $=$ qualtrics\&matchtype $=e \& d e v i c e=c \&$ placement $=\&$ network $=$ g\&creative $=409835850614 \&$ gclid $=$ CjwKCAiAj_xBRBjEiwAmRbqYpxd28hIFmAIB8p8clii1ZAHJRUVZdj09B4rTuaGIXLsazN7iU9dxoCzKYQAvD_BwE

Ragins, B. R., Ehrhardt, K., Lyness, K. S., Murphy, D. D., \& Capman, J. F. (2017). Anchoring relationships at work: High-quality mentors and other supportive work relationships as buffers to ambient racial discrimination. Personnel Psychology, 70(1), 211-256.

Rai, A. and Agarwal, U.A. (2017) 'Workplace bullying among Indian managers: prevalence, sources and bystanders' reactions', Int. J. Indian Culture and Business Management, Vol. 15, No. 1, pp.58-81. 


\section{EVERYBODY KNOWS: WITNESSING WORKPLACE HARASSMENT}

Rasul, I., \& Rogger, D. (2015). The impact of ethnic diversity in bureaucracies: Evidence from the Nigerian civil service. The American Economic Review, 105, 457-61.

Ray, B., \& Preston, V. (2015). Working with diversity: A geographical analysis of ethno racial discrimination in Toronto. Urban Studies, 52, 1505-1522.

Reicher, S., \& Hopkins, N. (2000). Self and nation. Sage.

Rayner, C. and Bowes-Sperry, L. (2008), Mobilizing bystanders to intervene in workplace bullying. In the 6th International Conference on Workplace Bullying and Harassment, Montreal.

Ross, A. (2016, August 10). Half of women in UK have been sexually harassed at work, study finds. The Guardian. London. Retrieved from https://www.theguardian.com/lifeandstyle/2016/aug/10/half-of-women-uk-have-beensexually-harassed-at-work-tuc-study-everyday-sexism

Shannon, C. A., Rospenda, K. M., Richman, J. A., \& Minich, L. M. (2009). Race, racial discrimination, and the risk of work-related illness, injury, or assault: Findings from a national study. Journal of Occupational and Environmental Medicine, 51(4), 441448.

Sias, P.M. and Jablin, F.M. (1995), "Differential superior-subordinate relations, perceptions of fairness, and co-worker communication", Human Communication Research, Vol. 22 No. 1, pp. 5-38.

Silverschanz, P., Cortina, L. M., Konik, J., \& Magley, V. J. (2008). Slurs, snubs, and queer jokes: Incidence and impact of heterosexist harassment in academia. Sex Roles, 58(34), 179-191.

Survey Circle (n.d.) retrieved 2nd September 2019, from https://www.surveycircle.com/en/

Talk to Spot (n.d.) retrieved 2nd September 2019, from https://talktospot.com 


\section{EVERYBODY KNOWS: WITNESSING WORKPLACE HARASSMENT}

Taylor, P., Mcloughlin, C., Meyer, D., \& Brooke, E. (2013). Everyday discrimination in the workplace, job satisfaction and psychological wellbeing: age differences and moderating variables. Ageing \& Society, 33, 1105-1138.

TimesUp (n.d.) retrieved 2nd September 2019, from https://www.timesupnow.com

Triana, M. del C., Jayasinghe, M., \& Pieper, J. R. (2015). Perceived workplace racial discrimination and its correlates: A meta-analysis. Journal of Organizational Behavior, 36(4), 491-513.

TUC (2019). Sexual harassment of LGBT people in the workplace. Retrieved, $10^{\text {th }}$ February 2019 , from https://www.tuc.org.uk/sites/default/files/LGBT_Sexual_Harassment_Report_0.pdf

Vault (n.d.), retrieved 2nd September 2019, from https://vaultplatform.com

Vaidyam, A. N., Wisniewski, H., Halamka, J. D., Kashavan, M. S., \& Torous, J. B. (2019). Chatbots and conversational agents in mental health: a review of the psychiatric landscape. The Canadian Journal of Psychiatry, 64(7), 456-464.

Willness, C. R., Steel, P., \& Lee, K. (2007). A meta-analysis of the antecedents and consequences of workplace sexual harassment. Personnel Psychology, 60(1), 127162.

Woebot (n.d.), retrieved 2nd September 2019, from https://woebot.io

Women in the City (n.d.) retrieved 2nd September 2019, from http://www.citywomen.co.uk 


\section{Appendices}

\section{Appendix 1}

\section{Harassment Reporting Model (HRM) Questions}

Q1. Allow witnesses to stay anonymous

Q2. Give people choices about how they want to report (e.g. online, to a human, to a hotline)

Q3. Get HR to encourage witnesses to report

Q4. Make it easier for witnesses to report

Q5. Allow witnesses to report via an automated system online

Q6. Remind witnesses regularly how to report

Q7. Allow witnesses to report via a third party

Q8. Create targeted training programmes (e.g. management training)

Q9. Provide harassment hotline

Q10. Remove conflicts of interest (e.g. person handling harassment case related to perpetrator)

Participants were given the following response options that related to a) how positively/negatively the suggestion was perceived to be and b) whether or not the workplace already had this suggestion in place:

HR in my workplace already does this. It has NOT made reporting better (coding score $=1$ ) HR in my workplace does not do this. It would NOT make reporting better (coding score $=2$ ) $H R$ in my workplace does not do this. It would make reporting better (coding score $=3$ ) $H R$ in my workplace already does this, and it has made reporting better (coding score $=4$ )

The highest score (4) is for a positive perception of an item already in place in a workplace, followed by a positive perception of an item not already in place (3). This is followed by a negative perception of an item not already in place (2), and the lowest score (1) was given to a negative perception of an item already in place in a workplace.

\section{Appendix 2 WHM Correlation Matrix}


EVERYBODY KNOWS: WITNESSING WORKPLACE HARASSMENT

\begin{tabular}{lllllllllll} 
& & Q1 & Q2 & Q3 & Q4 & Q5 & Q6 & Q8 & Q9 & Q10 \\
\hline Correlation & Q1 & 1.00 & 0.60 & 0.56 & 0.57 & 0.35 & 0.31 & 0.32 & 0.23 & 0.40 \\
& Q2 & 0.60 & 1.00 & 0.57 & 0.64 & 0.50 & 0.40 & 0.38 & 0.21 & 0.41 \\
& Q3 & 0.56 & 0.57 & 1.00 & 0.61 & 0.46 & 0.45 & 0.40 & 0.35 & 0.37 \\
& Q4 & 0.57 & 0.64 & 0.61 & 1.00 & 0.51 & 0.41 & 0.28 & 0.27 & 0.42 \\
& Q5 & 0.35 & 0.50 & 0.46 & 0.51 & 1.00 & 0.41 & 0.32 & 0.42 & 0.39 \\
& Q6 & 0.31 & 0.40 & 0.45 & 0.41 & 0.41 & 1.00 & 0.38 & 0.42 & 0.36 \\
& Q8 & 0.32 & 0.38 & 0.40 & 0.28 & 0.32 & 0.38 & 1.00 & 0.31 & 0.42 \\
& Q9 & 0.23 & 0.21 & 0.35 & 0.27 & 0.42 & 0.42 & 0.31 & 1.00 & 0.40 \\
& Q10 & 0.40 & 0.41 & 0.37 & 0.42 & 0.39 & 0.36 & 0.42 & 0.40 & 1.00 \\
\hline Sig. (1-tailed) & Q1 & & 0.00 & 0.00 & 0.00 & 0.00 & 0.00 & 0.00 & 0.00 & 0.00 \\
& Q2 & 0.00 & & 0.00 & 0.00 & 0.00 & 0.00 & 0.00 & 0.00 & 0.00 \\
& Q3 & 0.00 & 0.00 & & 0.00 & 0.00 & 0.00 & 0.00 & 0.00 & 0.00 \\
& Q4 & 0.00 & 0.00 & 0.00 & & 0.00 & 0.00 & 0.00 & 0.00 & 0.00 \\
& Q5 & 0.00 & 0.00 & 0.00 & 0.00 & & 0.00 & 0.00 & 0.00 & 0.00 \\
& Q6 & 0.00 & 0.00 & 0.00 & 0.00 & 0.00 & & 0.00 & 0.00 & 0.00 \\
& Q8 & 0.00 & 0.00 & 0.00 & 0.00 & 0.00 & 0.00 & & 0.00 & 0.00 \\
& Q9 & 0.00 & 0.00 & 0.00 & 0.00 & 0.00 & 0.00 & 0.00 & & 0.00 \\
& Q10 & 0.00 & 0.00 & 0.00 & 0.00 & 0.00 & 0.00 & 0.00 & 0.00 & \\
\hline
\end{tabular}

